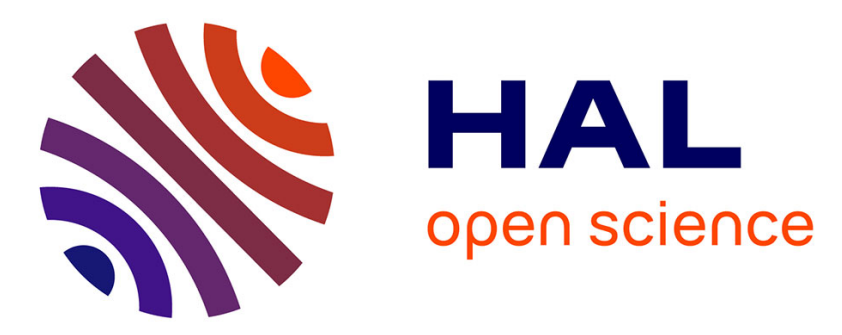

\title{
Two-dimensional discrete element models of debris avalanches: Parameterization and the reproducibility of experimental results
}

\author{
J. Banton, P. Villard, Denis Jongmans, C. Scavia
}

\section{- To cite this version:}

J. Banton, P. Villard, Denis Jongmans, C. Scavia. Two-dimensional discrete element models of debris avalanches: Parameterization and the reproducibility of experimental results. Journal of Geophysical Research, 2009, 114, pp.F04013. 10.1029/2008JF001161 . insu-00498396

HAL Id: insu-00498396

https://hal-insu.archives-ouvertes.fr/insu-00498396

Submitted on 3 Mar 2021

HAL is a multi-disciplinary open access archive for the deposit and dissemination of scientific research documents, whether they are published or not. The documents may come from teaching and research institutions in France or abroad, or from public or private research centers.
L'archive ouverte pluridisciplinaire HAL, est destinée au dépôt et à la diffusion de documents scientifiques de niveau recherche, publiés ou non, émanant des établissements d'enseignement et de recherche français ou étrangers, des laboratoires publics ou privés. 


\title{
Two-dimensional discrete element models of debris avalanches: Parameterization and the reproducibility of experimental results
}

\author{
J. Banton, ${ }^{1}$ P. Villard, ${ }^{2}$ D. Jongmans, ${ }^{1}$ and C. Scavia ${ }^{3}$ \\ Received 27 September 2008; revised 8 July 2009; accepted 5 August 2009; published 3 November 2009.
}

[1] Application of the discrete element method (DEM) to model avalanches of granular materials requires determining the correct geometric and rheological parameters for and between the particles as well as for the basal surface. The use of spherical (circular in 2-D) particles enhances particle rolling, yielding excessive runout values. The solution usually adopted to correct this effect is to introduce a drag force which artificially slows down the particle velocities. The aim of this study is to test the capability of the DEM to simulate well-controlled unsteady channelized granular flows, considering the measured properties of the particles and of the basal surface which naturally contribute to dissipate energy. We first performed a parametrical analysis on a simple 2-D model in order to estimate the influence of particle shape, friction parameters, and restitution coefficients on the dynamics of the flow and on the deposit geometry. We then simulated three channelized laboratory experiments performed with two materials and two bed linings. Using the geometrical layout and the values of the mechanical parameters provided by the authors, we obtained a remarkable agreement between the observed and 2-D simulated deposit shapes for the three experiments. Also, the computed mass evolution with time was very consistent with the experimental snapshots in all cases. These results highlight the capability of the DEM technique for modeling avalanche of granular material when the particle shape as well as the friction and restitution coefficients are properly considered.

Citation: Banton, J., P. Villard, D. Jongmans, and C. Scavia (2009), Two-dimensional discrete element models of debris avalanches: Parameterization and the reproducibility of experimental results, J. Geophys. Res., 114, F04013, doi:10.1029/2008JF001161.

\section{Introduction}

[2] Granular flows on inclined planes are common phenomena in earth sciences, involving snow avalanches, rock avalanches, debris flows and pyroclastic flows. Among these, rock avalanches are potentially catastrophic events which are initiated on steep slopes and can travel surprisingly long distances [Hsu, 1975; Legros, 2002; Hungr and Evans, 2004], posing a crucial problem for the safety of settlements. The long runouts relative to drop heights for rock avalanches were first noted in the pioneering work of Heim [1932] and have been intensively studied since then by Hsu [1975], Corominas [1996], Davies et al. [1999], Legros [2002], and Hungr and Evans [2004]. However, none of the numerous mechanisms put forward to explain the high mobility of rock avalanches (for a review, see Davies et al. [1999], Erismann and Abele [2001], Legros

\footnotetext{
${ }^{1}$ Laboratoire de Géophysique Interne et Tectonophysique, UMR 5559, Observatoire des Sciences de l'Univers, Université Joseph Fourier, CNRS, Grenoble, France.

${ }^{2}$ Laboratoire 3S-R, Université Joseph Fourier, G-INP, CNRS, Grenoble, France.

${ }^{3}$ Department of Structural and Geotechnical Engineering, Politecnico di Torino, Turin, Italy.

Copyright 2009 by the American Geophysical Union. 0148-0227/09/2008JF001161
}

[2002], and Friedmann et al. [2006]) is universally accepted and the problem of the extraordinary mobility of rock avalanches is still unresolved and controversial.

[3] Field data during rock avalanches are rare and information gathered after the events is limited due to the difficulty of conducting field analyses. In addition, rock avalanches can be extremely complex in terms of geometry and grain size distribution [Crosta et al., 2007], making difficult a validation of models. In view of these difficulties, laboratory experiments have been widely used to gain insight into the mechanics of rock avalanches [see, e.g., Hungr and Morgenstern, 1984; Hutter et al., 1995; Davies and McSaveney, 1999; Davies et al., 1999; Denlinger and Iverson, 2001; Goujon et al., 2003; Iverson et al., 2004; Friedmann et al., 2006; Manzella and Labiouse, 2008; Goujon et al., 2007]. Laboratory experiments permit control of the rheological and geometrical properties, as well as the computation of velocities and particle densities using fast cameras and image processing techniques [Lajeunesse et al., 2005; Friedmann et al., 2006; Valentino et al., 2008]. Many laboratory experiments have shown morphologies similar to natural deposits, including longitudinal and transverse ridges, frontal and lateral levees, and vertical segregation [Friedmann et al., 2006]. Nevertheless, long runout values have not yet been obtained in the laboratory, either because some important conditions cannot be attained in experiments or because one or several additional physical 
phenomena are necessary to explain the high mobility values [Friedmann et al., 2006].

[4] Numerical simulations have also been widely used to study long-runout rock avalanches and testing the proposed models. Two main families of methods can be distinguished: continuum mechanics methods and granular methods. Since the pioneering work of Voellmy [1955], continuum hydrodynamic models based on the depth-averaged (Saint Venant) equations have been continuously developed to reproduce features of both experimental and real size unsteady granular flows [e.g., Savage and Hutter, 1989; Hungr, 1995; Denlinger and Iverson, 2001; Davies and McSaveney, 2002; Pouliquen and Forterre, 2002; Mangeney-Castelnau et al., 2003; Denlinger and Iverson, 2004; McDougall and Hungr, 2004, 2005; Pirulli et al., 2007]. All these methods however require a suitable choice of input parameters and their proper calibration at the relevant scale, which is a difficult and nonunique problem when only geometrical data on the avalanche deposit are available [Crosta et al., 2003].

[5] In recent years, another modeling approach, the discrete element method (DEM), initially introduced by Cundall [1971], has emerged in earth sciences, particularly for simulating avalanches of granular materials. DEM is based on the idea that the interaction of a large number of small entities, the behavior of which is well known, allows larger-scale aggregate system behavior to be studied and understood [Richards et al., 2004]. Different discrete element methods have been developed, which can again be split into two main families: smooth methods [Cundall and Strack, 1979; Cundall, 1987] which allow overlapping between particles in contact (the molecular dynamics approach) and nonsmooth methods [Moreau, 1988, 1993; Radjai et al., 1998; Jean, 1999] considering rigid interaction between particles (the contact dynamics approach). DEM offers a means of simulating granular avalanches through the motion and multiple collisions of thousands (or more) of deformable, frictional and rotating particles interacting together. It has been increasingly applied to model granular flows using both the contact dynamics algorithm [Staron and Hinch, 2007; Staron, 2008] and, more frequently, the smooth particle molecular dynamics algorithm [e.g., Campbell et al., 1995; Crosta et al., 2001; Morgan and McGovern, 2003; Cleary and Prakash, 2004; Morgan and McGovern, 2005; Linares-Guerrero et al., 2007; Valentino et al., 2008]. Campbell et al. [1995] simulated large-scale landslides with a simplified ground contour and a number of 2-D circular discs ranging from 5000 to 1 million. They used a coefficient of restitution of 0.1 for a collision between two particles, implying that $99 \%$ of the energy is dissipated during such a binary collision. They emulated many of the features of field observations, including the preservation of stratum order and the volumetric effect of runout. Morgan and McGovern [2003] showed 2-D DEM model results of volcanic spreading, which compare favorably to morphologic features noted on Olympus Mons (Mars). In their simulations, they used circular particles which enhanced rolling. In order to attain realistic shear strengths, particle rotations are restricted and energy is dissipated at the contacts by viscous or force damping. Cleary and Prakash [2004] simulated the collapse of a mountain peak in Northern California and predicted the propagation of the $2.5 \times 10^{6} \mathrm{~m}^{3}$ rock mass over real $3-\mathrm{D}$ topography, using 166,000 particles with size in the range 2-10 m. Recently, Linares-Guerrero et al. [2007] simulated 2-D avalanches of two size particles (with a diameter ratio from 2 to 8.33) and showed that the runout increases with the area fraction of smaller particles. If the DEM potential for modeling rock avalanches has been demonstrated, the validation of DEM predictions on real cases remains a major problem, due to the scarcity of measurements and data during rock avalanches [Cleary and Prakash, 2004]. Of particular concern are the particle-scale input parameters required to generate correct behavior at the rock avalanche scale. Laboratory experiments could provide well-controlled data which can be used for DEM validation. Calvetti et al. [2000] and Crosta et al. [2001] used 2-D DEM models to simulate one of the laboratory experiments performed by Hutter et al. [1995] with disc-like shaped plastic particles. Using the input parameters provided by the authors and 1256 circular particles, they satisfactory reproduced the experimental results. They however had to introduce an artificial force damping of 0.03 in order to fix the correct position and shape of the deposit, presumably in part because the use of circular particles enhances particle rolling and yields excess runout values. The force damping employed therefore acts like a drag force which artificially slows down the particle velocities but then leads to unrealistic runout times.

[6] The aim of this paper is to test the capability of the DEM to simulate well-controlled unsteady channelized granular flows, by only considering the particle and basal surface properties measured in the laboratory (particle shape, friction and restitution coefficients) and which are likely to dissipate energy naturally. We first performed a sensitivity analysis on a simple 2-D model in order to estimate the influence of these properties on the dynamics of the flow and on the deposit geometry. We then simulated three laboratory experiments carried out by Savage and Hutter [1991] and Hutter al. [1995] on the motion on several cohesionless granular materials released from rest down a rough incline with a high slope. For such granular flows well channelized between two smooth walls, fast camera images taken from above showed small sidewall effects and no cross-flow motions [Lajeunesse et al., 2005; Valentino et al., 2008]. Two-dimensional modeling of the flows can then be applied. The three physical experiments used two materials (nearly spherical glass beads and lenslike-shaped plastic particles) with different volumes and bed linings (drawing paper and sandpaper). Using the geometrical data and the values of the mechanical parameters provided by the authors, a remarkable agreement was reached between the observed and simulated deposit shapes for the three experiments without introducing numerical damping. The computed granular mass propagation is also very consistent with the experimental snapshots in all cases.

\section{Discrete Element Method}

[7] In the molecular dynamics approach (smooth method), DEM assumes a set of particles interacting with each other through deformable contact points. Interaction laws, locally defined, make it possible to restore a global macroscopic behavior of the particle assembly. The discrete element model used for this study is the two dimensional software 


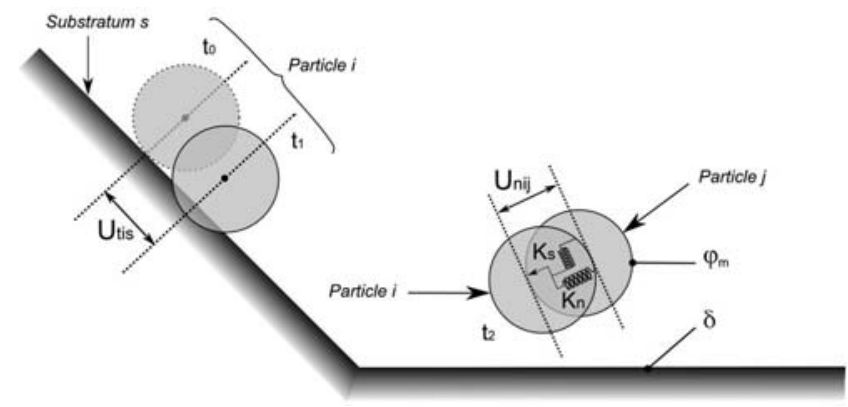

Figure 1. (right) Contact parameters $K s, K n$, and $\varphi_{m}$ between two colliding particles $i$ and $j$. $U_{n i j}$ is the particle overlap. (left) Contact parameters between substratum and the colliding particle $i . U_{\text {tis }}$ is the relative tangential displacement between the particle and the substratum.

PFC $^{2 \mathrm{D}}$ [Itasca Consulting Group, 1996]. The granular material is modeled using a collection of elementary discs which may be assembled together to generate clusters. The particle or cluster set up is generated randomly at fixed porosity in a polygonal area using the Radius Expansion with Decrease of Friction process (REDF) [Deluzarche et al., 2003; Chareyre and Villard, 2005]. In this method, the particle diameters are progressively increased and the contact friction coefficient is reduced in order to obtain the desired porosity and to maintain a low value for the isotropic pressure acting at boundaries. The displacement boundary conditions were imposed using rigid frictional walls. The elastic behavior of the assembly of two particles $i$ and $j$ depends on two local contact parameters: the normal stiffness $K_{n}$ and the shear stiffness $K_{s}$ (Figure 1) which are defined by

$$
\begin{aligned}
K_{n} & =\left(k_{n i} \times k_{n j}\right) /\left(k_{n i}+k_{n j}\right) \\
K_{s} & =\left(k_{s i} \times k_{s j}\right) /\left(k_{s i}+k_{s j}\right)
\end{aligned}
$$

where $k_{n i}, k_{n j}, k_{s i}$, and $k_{s j}$ are the normal and shear stiffness values for particles $i$ and $j$, respectively. The REDF process, applied to discs or clumps, ensures the isotropy of the orientation and intensity of contact forces [Salot et al., 2009]. Because of the low considered porosity value, applying gravity does not change the microstructure of the assembly of particles. Isotropy of contacts was kept but not the one of contact forces, owing to the application of vertical gravity forces. Two contact failure criteria were defined [Itasca Consulting Group, 1996]: one under tension relying on the tensile strength limit $R_{t}$, and a derived Coulomb friction law as the shear criterion [Cundall and Strack, 1979]. This last criterion requires two parameters: the shear strength $R_{s}$ (independent of the normal force) and the microscopic friction angle $\varphi_{m}$.

$$
\varphi_{m}=\min \left(\varphi_{m i}, \varphi_{m j}\right)
$$

where $\varphi_{m i}$ and $\varphi_{m j}$ are the local microscopic friction angles for each particle. The normal contact force $F_{n}$ between two particles $i$ and $j$ (Figure 1) is expressed by

$$
F_{n}=K_{n} U_{n i j}
$$

where $U_{n i j}$ is the overlap between the two particles. The tangential contact force $F_{S}$ is linked to the tangential incremental relative displacement $U_{t i j}$ between particles $i$ and $j$ by the equation

$$
\begin{gathered}
\mathrm{d}\left(F_{s}\right) / \mathrm{d}\left(U_{t i j}\right)=K_{s} \\
\text { with } F_{s} \leq \max \left[R_{s}, F_{n} \tan \left(\varphi_{m}\right)\right]
\end{gathered}
$$

The interactions between one particle and the substratum are ruled by the same equations as those defined between two particles, replacing the stiffness values for one particle $\left(k_{n i}\right.$ and $\left.k_{s i}\right)$ by those for the substratum $\left(k_{n s}\right.$ and $\left.k_{s s}\right)$, and $\varphi_{m i}$ by the substratum microscopic friction angle $\delta$.

[8] Numerical resolution of the equations of motion is based on the discretization of time into intervals $\Delta t$. As all the forces applied to particles are known, displacements and rotations can be integrated on $\Delta t$ following an explicit, finite difference formulation of the traditional laws of dynamic motion [Allen and Tildesley, 1987]. Contact forces are then recalculated for the following time step. In order to limit the dynamic effects and to insure the convergence of the numerical process Cundall [1987] introduces an artificial force damping, modifying the law of dynamic motion as follows:

$$
F_{k}-\chi\left|F_{k}\right| \operatorname{sign}\left(V_{k}\right)=m \gamma_{k}
$$

where $\chi$ is the force damping coefficient, $m$ is the mass and $V_{k}$ and $\gamma_{k}$ are the component $k$ of velocity and of acceleration for one particle, respectively. Note that sign $\left(V_{k}\right)=1$ if $V_{k}>0$, sign $\left(V_{k}\right)=-1$ if $V_{k}<0$ and $\operatorname{sign}\left(V_{k}\right)=0$ if $V_{k}=0$. However, this use of a force damping for dynamic applications induces an artificial energy dissipation, causing a nonphysical slowing down of the particles and unrealistic long runout times. As an alternative, local contact laws have been proposed that dissipate energy during the impact between two bodies [Walton and Braun, 1986; Schäfer et al., 1996; Oger et al., 1998], introducing viscosity (function of the impact velocity) or restitution coefficients (integrating plasticity, crushing or breaking at contact point). The main difficulties with these local contact laws lie in the definition and determination of relevant parameters. In this study, incremental equations (8) and (9) were used instead of equation (4) to introduce the rebound coefficient $C R$ in the normal contact laws between two particles (called $C R d$ ) or between a substratum and a particle (called $C R s)$ :

$$
\begin{gathered}
\mathrm{d} F_{n}=k_{n} \mathrm{~d} U n_{i j} \text { if } \mathrm{d} U_{n i j}>0 \\
F_{n}=C R k_{n} U n_{i j} \text { if } \mathrm{d} U_{n i j}<0
\end{gathered}
$$

where $\mathrm{d} U n_{i j}$ is the incremental normal overlapping displacement. It is positive when the particles move closer (contraction) and negative when particles move away (expansion). For each time step and at each contact point, external forces are added to correct normal contact forces, satisfying equations (8) and (9). This introduction induces a greater computation time but does not require to 


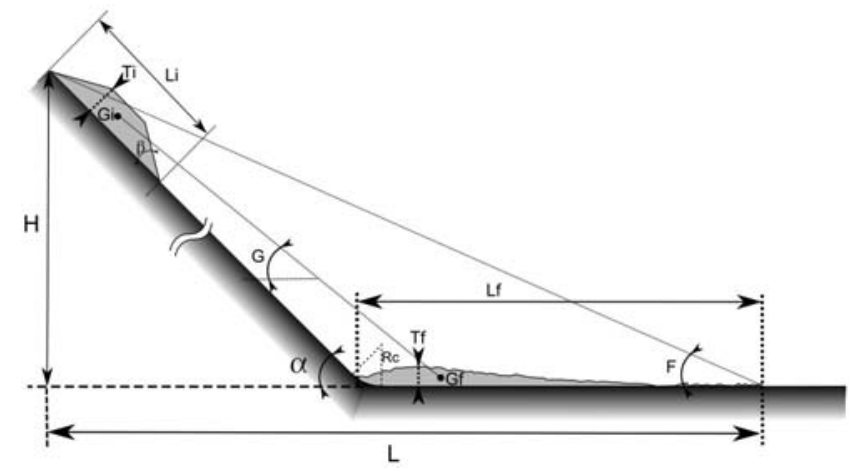

Figure 2. Reference geometry and variables used in the model. $L_{i}, T_{i}, \beta$, and $G_{i}$ are basal length, thickness, basal angle, and center of mass in its initial position. $L_{f}, T_{f}$, and $G_{f}$ are basal length, maximum thickness, and center of mass of the deposit after motion. $H$, fall height; $L$, length between the rear of the initial mass and the front of the deposit; $\alpha$, slope angle of the inclined plane; $R c$, curvature radius of the circular section; $F$, Fahrböschung (see text for definition); $G$, travel angle.

modify the global scheme of resolution implemented in the $\mathrm{PFC}^{2 \mathrm{D}}$ code.

[9] For a particle bouncing off the substratum, $C R$ is defined as the kinetic energy ratio before and after the impact:

$$
C R=\left(V_{f} / V_{i}\right)^{2}
$$

where $V_{i}$ and $V_{f}$ are the approaching and the rebound particle velocities normal to the surface. $C R$ can also be expressed as the ratio of the bounce and drop heights (normal impact) and can be determined from simple rebound experiments. In situ experiments [Pfeiffer and Bowen, 1989; Evans and Hungr, 1993] showed that the restitution coefficient values $(R e=\sqrt{ } C R)$ are between 0.9 and 0.3 for a substratum made of hard rock and soil, respectively. In the model used, energy dissipation in the tangential direction is obtained by friction when the maximal tangential force (equation (6)) is obtained during the overlapping. The parameters governing this dissipative phenomenon are the normal stiffness $K_{n}$, the shear stiffness $K_{s}$ and the microscopic friction angle $\varphi_{m}$.

\section{Parametric Study of 2-D Granular Flows \\ 3.1. Geometrical Layout and Parameters}

[10] The reference frame for the DEM simulations (Figure 2) is an inclined plane with a large inclination $\alpha=45^{\circ}$, linked to a horizontal plane by a circular section with a curvature radius $R c$. The granular mass is placed at the top of the inclined plane at height $H$ in an isosceles trapezoidal box with a basal length $L_{i}$, a thickness $T_{i}$ and a basal angle $\beta$. Gravity is first applied and, after stabilization of the granular mass under its own weight, the walls of the trapezoid box are deleted. The granular mass flows until stabilization of the particles. The deposit is characterized by its maximum thickness $T_{f}$ and its length $L_{f}$, which is the distance between the front position $\left(X_{\text {front }}\right)$ and the rear position $\left(X_{\text {rear }}\right)$ of the deposit, and by the standard deviation $\sigma$ of the particle distribution around the center of mass. The runout $L$ is the maximum horizontal distance between the left corner of the trapezoidal mass and the distal end of the deposit. The angle $F$ given by $\tan (F)=H / L$ was called Fahrböschung by Heim [1932] and characterizes the mobility of the avalanche. Another parameter of interest is the travel angle $G$ defined by the line joining the centers of mass of the initial trapezoid mass $\left(G_{i}\right)$ and of the final deposit $\left(G_{f}\right)$. When considered particles are circular, they can individually roll in front of the deposit if they are ejected from the front of the mass. The front position $\left(X_{\text {front }}\right)$ of the deposit is defined as the distance over which the spacing between two successive particles is greater than 40 times the average particle diameter, which in most cases corresponds to the distance below which $99 \%$ of the particles are located. The same spacing criterion (with a threshold of 7.5 the particle diameter) is applied for defining the rear position $\left(X_{\text {rear }}\right)$ of the deposit.

[11] Numerical simulations of unsteady granular flows were performed to determine the significant parameters controlling the avalanche and deposit characteristics, focusing on the mechanisms dissipating energy. The geometrical layout and the stiffness parameters are kept constant for all models (see Table 1). The initial porosity in the trapezoidal box is fixed to $18 \%$ and the granular material is considered as noncohesive $\left(R_{t}=R_{s}=0\right)$. Parameters varying in the simulations are the particle shape, the interparticle and substratum friction angles $\left(\varphi_{m}\right.$ and $\left.\delta\right)$ as well as the rebound coefficients $C R d$ (between particles) and $C R s$ (between particles and substratum). More than 50 numerical simulations were performed, and Table 2 shows the parameter values for the 15 selected models whose results are presented in this paper. Also given in Table 2 are the geometrical characteristics of the final deposit as well as parameters characterizing the flow of the $N_{d}$ particles present in a $20 \mathrm{~m}$ wide box at a time $t_{s}$ of about $15 \mathrm{~s}$ after the release: the mean particle velocity $V_{m}$ and the coordination number $\zeta$, defined by the ratio between the number of contacts and the number of particles. This last parameter is mainly controlled by the flow density.

\subsection{Particle Shape Influence}

[12] Three types of particle were used (labeled A to C in Figure 3). Particles of type A are simple circular discs of

Table 1. Geometrical and Rheological Parameters Common to All Models $^{\mathrm{a}}$

\begin{tabular}{lll}
\hline Parameter & \multicolumn{1}{c}{ Value } \\
\hline & Particle & \\
$k_{n i}[\mathrm{~N} / \mathrm{m}]$ & & $1.5 \times 10^{8}$ \\
$k_{s i}[\mathrm{~N} / \mathrm{m}]$ & & $1.5 \times 10^{8}$ \\
$\rho_{i}\left[\mathrm{~kg} / \mathrm{m}^{3}\right]$ & Substratum & 3283 \\
$k_{n s}[\mathrm{~N} / \mathrm{m}]$ & & $1.5 \times 10^{8}$ \\
$k_{s s}[\mathrm{~N} / \mathrm{m}]$ & Trapezoidal Box & $1.5 \times 10^{8}$ \\
$\beta\left[^{\circ}\right]$ & & 30 \\
$L_{i}[\mathrm{~m}]$ & & 86.7 \\
$T_{i}[\mathrm{~m}]$ & & 17.3 \\
$\alpha\left[{ }^{\circ}\right]$ & Inclined Plane & 45 \\
$R c[\mathrm{~m}]$ & & 45 \\
$H[\mathrm{~m}]$ & & 364.6 \\
\hline
\end{tabular}

${ }^{\mathrm{a}}$ See text for details. 
Table 2. Model, Flowing, and Deposit Geometrical Parameters for the 16 Selected Models ${ }^{\mathrm{a}}$

\begin{tabular}{|c|c|c|c|c|c|c|c|c|c|c|c|c|c|c|c|}
\hline \multirow[b]{2}{*}{ Model } & \multicolumn{5}{|c|}{ Model Parameters } & \multicolumn{4}{|c|}{ Flow Parameters } & \multicolumn{6}{|c|}{ Deposit Parameters } \\
\hline & Type & $\varphi_{m}(\mathrm{deg})$ & $\delta(\mathrm{deg})$ & $C R d$ & $C R s$ & $t_{s}(\mathrm{~s})$ & $\zeta$ & $N_{d}$ & $V_{m}$ & $L(\mathrm{~m})$ & $F(\mathrm{deg})$ & $G(\mathrm{deg})$ & $\sigma(\mathrm{m})$ & $L f(\mathrm{~m})$ & $T f(\mathrm{~m})$ \\
\hline $1^{\mathrm{b}}$ & A & 25 & 25 & 1 & 1 & 15.13 & 0.2 & 47 & 46.8 & 1195.8 & 17.0 & 25.7 & 139.2 & 721.5 & 3.4 \\
\hline $2^{\mathrm{b}}$ & B & 25 & 25 & 1 & 1 & 15.02 & 0.2 & 150 & 46.3 & 1122.9 & 18.0 & 29.2 & 115.1 & 664.8 & 4.9 \\
\hline $3^{\mathrm{b}}$ & $\mathrm{C}$ & 25 & 25 & 1 & 1 & 15.25 & 2.4 & 168 & 47.5 & 842.4 & 23.5 & 31.9 & 58.9 & 362.4 & 8.3 \\
\hline 4 & $\mathrm{C}$ & 26 & 26 & 1 & 1 & 14.00 & 1.4 & 222 & 45.9 & 876.0 & 22.7 & 33.0 & 62.0 & 423.0 & 9.6 \\
\hline 5 & C & 27 & 27 & 1 & 1 & 14.08 & 0.7 & 190 & 44.6 & 936.3 & 21.3 & 33.5 & 77.0 & 494.7 & 9.6 \\
\hline $6^{\mathrm{b}}$ & C & 28 & 28 & 1 & 1 & 14.13 & 0.4 & 217 & 43.7 & 935.4 & 21.4 & 33.4 & 88.7 & 527.1 & 7.2 \\
\hline 7 & $\mathrm{C}$ & 29 & 29 & 1 & 1 & 14.23 & 0.2 & 191 & 43.9 & 876.9 & 22.7 & 33.9 & 88.4 & 467.1 & 6.3 \\
\hline 8 & C & 30 & 30 & 1 & 1 & 14.24 & 0.2 & 211 & 43.0 & 946.2 & 21.1 & 33.9 & 93.6 & 541.5 & 6.6 \\
\hline $8 \mathrm{~b}$ & C & 32.5 & 32.5 & 1 & 1 & 14.30 & 0.1 & 186 & 42.9 & 987.6 & 20.3 & 34.4 & 96.6 & 607.5 & 6.2 \\
\hline $9^{\mathrm{b}}$ & C & 35 & 35 & 1 & 1 & 14.31 & 0.1 & 151 & 43.4 & 870.3 & 22.8 & 34.8 & 92.9 & 488.4 & 6.6 \\
\hline 10 & C & 30 & 25 & 1 & 1 & 13.96 & 2.0 & 248 & 47.5 & 789.6 & 24.9 & 31.9 & 56.2 & 320.4 & 7.9 \\
\hline $11^{\mathrm{b}}$ & $\mathrm{C}$ & 35 & 25 & 1 & 1 & 13.98 & 1.8 & 287 & 47.2 & 913.8 & 21.8 & 32.0 & 64.2 & 443.7 & 7.8 \\
\hline $12^{\mathrm{b}}$ & $\mathrm{C}$ & 35 & 30 & 1 & 1 & 14.25 & 0.1 & 196 & 42.7 & 1029.0 & 19.6 & 33.9 & 98.7 & 638.4 & 6.1 \\
\hline $13^{\mathrm{b}}$ & $\mathrm{C}$ & 25 & 25 & 0.2 & 1 & 14.91 & 2.6 & 178 & 47.2 & 713.7 & 27.2 & 31.9 & 58.9 & 253.2 & 7.2 \\
\hline $14^{\mathrm{b}}$ & $\mathrm{C}$ & 25 & 25 & 1 & 0.2 & 15.93 & 0.2 & 142 & 38.8 & 790.8 & 24.8 & 38.0 & 73.1 & 424.8 & 8.0 \\
\hline $15^{\mathrm{b}}$ & $\mathrm{C}$ & 25 & 25 & 0.2 & 0.2 & 18.85 & 0.7 & 102 & 33.3 & 538.5 & 34.3 & 42.6 & 29.8 & 185.4 & 17.9 \\
\hline
\end{tabular}

${ }^{\mathrm{a}} \varphi_{m}$, interparticle friction angle; $\delta$, substratum friction angle; $C R d$, coefficient of rebound between two particles; $C R s$, coefficient of rebound between one particle and the substratum; $t_{s}$, time at which the flowing parameters have been determined; $\zeta$, coordination number (average number of contacts by particle); $N_{d}$, number of discs included in the $20 \mathrm{~m}$ wide box used to analyze the disc velocity vectors at $1 / 3$ of the initial elevation; $V_{m}$, mean velocity of the $N_{d}$ particles; $L$, horizontal distance between the upper part of the initial mass and the distal part of the deposit; $L_{f}$, final length of the deposit; $T_{f}$, maximum thickness of the deposit; $F$, Fahrböschung; $G$, Travel angle; $\sigma$, standard deviation of the particle distribution in the deposit.

${ }^{\mathrm{b}}$ The models for which results are shown.

radius $R=0.3 \mathrm{~m}$. Shape $\mathrm{B}$ particles are clumps of two overlapping discs of radius $R$, the centers of which are spaced apart by a distance $d=0.36 \mathrm{~m}$. Shape C particles are clusters of two discs of radius $R_{1}=0.3 \mathrm{~m}$ and $R_{2}=0.225 \mathrm{~m}$ jointed together by rigid contact laws. A minimum slight size dispersity of $10 \%$ is necessary to avoid crystallization and we took $30 \%$. A-type particles are perfect discs and can roll without dissipating energy. B-type particles are symmetrical and still have a rather regular shape which allows rolling, while C-type particles are asymmetrical and exhibit hollows which favor tangling. Particles are characterized by their shape factor $S f$, defined as the ratio of the length and width of the smallest rectangle surrounding a particle. Sf equals 1 for A-type particles, 1.6 for B-type particles, and 1.75 for C-type particles. The numbers of particles $N_{c}$ filling the trapezoidal box with a porosity of $18 \%$ are 2762, 1361, and 1735 for types A, B, and C, respectively. Preliminary tests have shown that the means of infilling the box has little influence on the granular mass propagation, making results reproducible for the given parameters.

[13] Figure 4 shows three snapshots of the particle avalanche at different times for the three particle types, as well as enlargement of a $20 \mathrm{~m}$ wide box showing the particle velocity vectors and the instantaneous velocity profile after a propagation time of about $15 \mathrm{~s}$. The box is located at one third of the fall height $H$ for all simulations. Comparison between the three graphs of Figure 4 and examination of Table 2 shows the predominant influence of the particle shape on the deposit geometry and location.
As expected, the greatest runout distance $L$ and the lowest travel angles $F$ and $G$ (Table 2) are reached for circular particles. The travel angle $G$ dramatically increases with the shape factor $S f$, from $25.7^{\circ}$ to $31.9^{\circ}$, yielding thicker and less dispersed deposits (low $\sigma$ values) for particles B and C. During the avalanche, the mean velocity $V_{m}$ computed in the box at the third of the fall height after a propagation time of about $15 \mathrm{~s}$ remains almost constant (about $47 \mathrm{~m} / \mathrm{s}$ ) for the three particle types. However, the particle velocity profiles and vectors (Figure 4) clearly show an influence of the particle shape on the flow which becomes denser and thinner with an increase of the shape factor. For particles $\mathrm{A}$ and $\mathrm{B}$, velocity vectors exhibit various orientations and particles move relatively freely in a $15 \mathrm{~m}$ thick flow, with a small number of between-grain contacts (low coordination number $\zeta=0.2$ ) and with velocities from $25 \mathrm{~m} / \mathrm{s}$ to $60 \mathrm{~m} / \mathrm{s}$, increasing from the interface to the flow top. On the contrary, the mass of C-type particles flows parallel to the substratum as a dense $3 \mathrm{~m}$ thick layer sliding with a near constant velocity. This behavior results from the shape of the particles which are entangled (high coordination number $\zeta=2.4$ ) and move together. The energy dissipated by frictional sliding at all contacts is given as a function of the release time in Figure 5 for the three particle types (models 1 to 3 for particles A to C, respectively). Frictional work rates grow similarly during the first $10 \mathrm{~s}$ of the flow, in relation with the increase of the mean particle velocity. At about $t=10 \mathrm{~s}$, the fastest particles $\mathrm{A}$ and $\mathrm{B}$ reach the horizontal plane and are thrown up, resulting in a dramatic
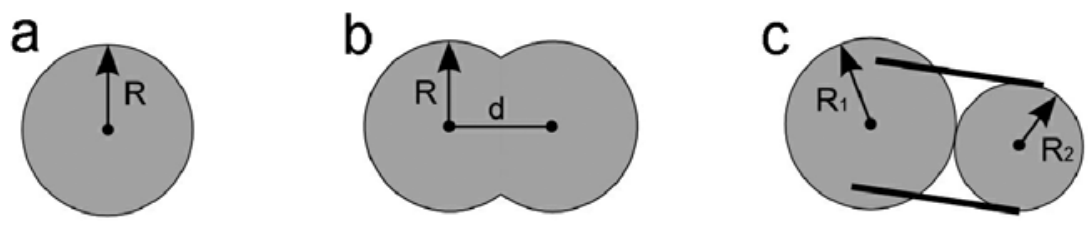

Figure 3. Geometry of the particles. (a) Type A, circular disc with a radius $R$. (b) Type B, clump of two overlapping particles $(d / R=1.2)$. (c) Type $\mathrm{C}$, cluster of two jointed particles $\left(R_{2} / R_{1}=0.75\right)$. 

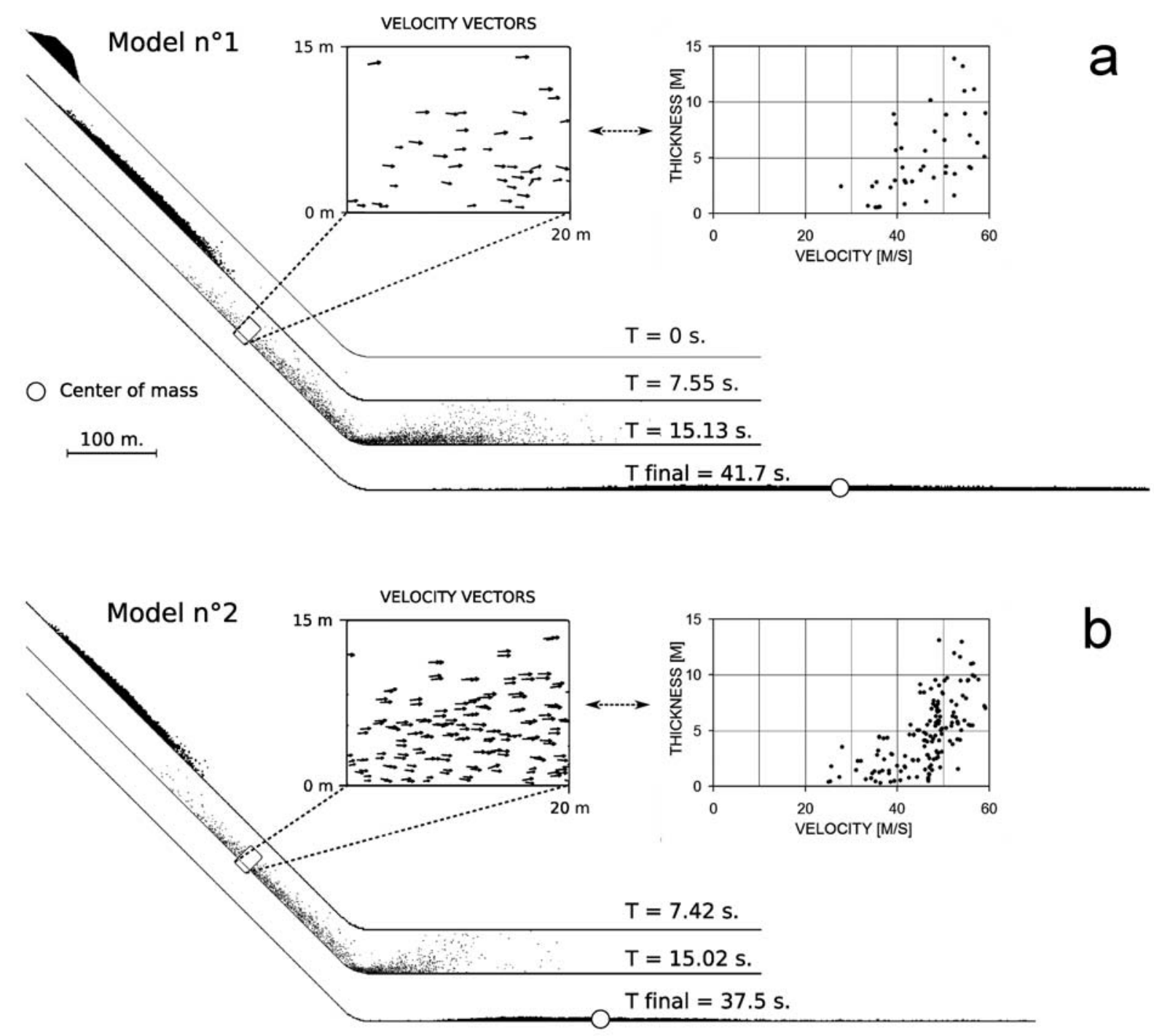

b

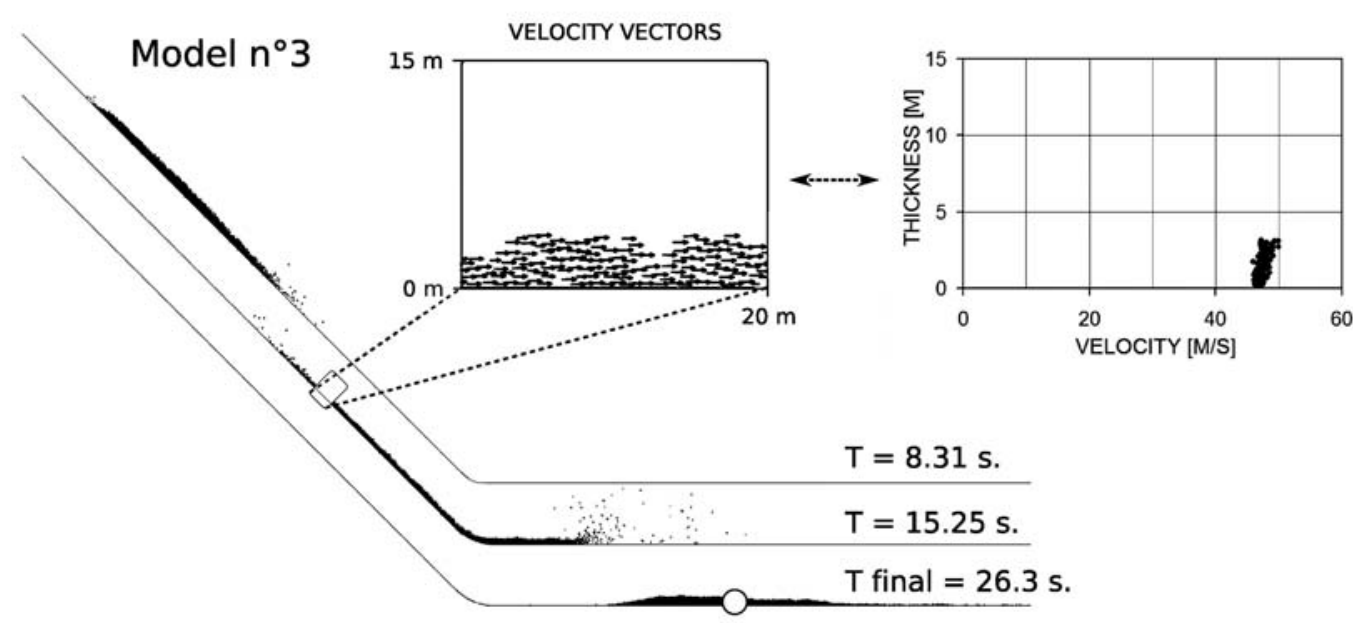

Figure 4. Snapshots of the granular flows for the three particle types shown in Figure 3. (a) Type A (circular discs), (b) type B (clumps), (c) type C (clusters). Here $\varphi_{m}=\delta=25^{\circ}$. CRd $=C R s=1$. An enlargement of the particle velocity vectors is shown around $15 \mathrm{~s}$ over a $20 \mathrm{~m}$ wide box located at $1 / 3$ of the fall height as well as the corresponding velocity profile. 


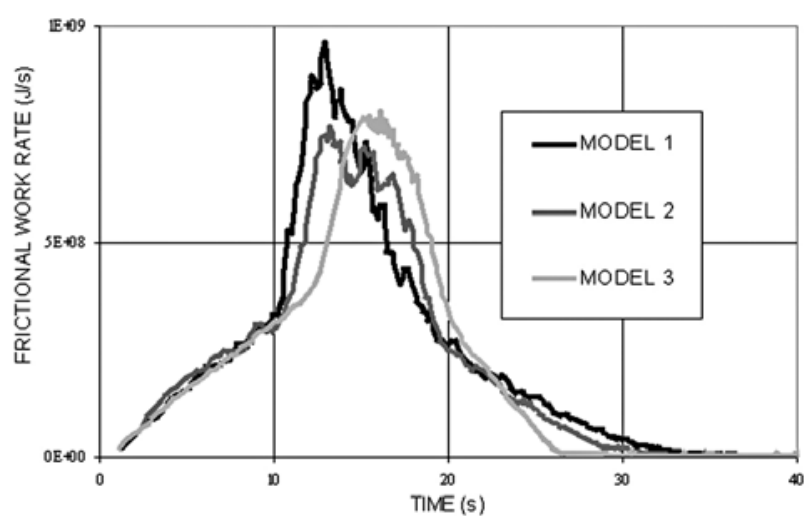

Figure 5. Frictional work rate versus release time for models 1, 2, and 3 (see Table 2 for details).

increase of the frictional work rate. This effect is delayed to $12 \mathrm{~s}$ after the release for particles $\mathrm{C}$ whose maximum velocity is less. After reaching a maximum, the three curves show a regular decrease, with a slope which steepens from particles A to C. This quick decrease of the frictional work rate for particles $\mathrm{C}$ arises because their rough shape prevents them from rolling and favors particle packing and compact deposits. On the contrary, A-type particles which tend to roll and dissipate energy slowly, resulting in a widely dispersed deposit.

\subsection{Sensitivity to Friction Parameters}

[14] This part of the study focuses on the joint influences of basal friction $\delta$ and particle friction $\varphi_{m}$ on the mass avalanche, with the two parameters having the same value.
In addition to model 3, six simulations (models 4 to 9 ) were performed with $\delta$ and $\varphi_{m}$ values ranging between $25^{\circ}$ and $35^{\circ}$ for C-type particles and for no energy dissipation during the shocks $(C R d=C R s=1)$. Snapshots and velocity vectors are shown for model $6\left(\delta=\varphi_{m}=28^{\circ}\right)$ and model $9\left(\delta=\varphi_{m}=\right.$ $35^{\circ}$ ) in Figures $6 \mathrm{a}$ and $6 \mathrm{~b}$, respectively. These can be compared to those of Figure $4 \mathrm{c}\left(\operatorname{model} 3 ; \delta=\varphi_{m}=25^{\circ}\right)$. A joint increase of the friction parameters (from $25^{\circ}$ to $35^{\circ}$ ) results in a larger dispersion of the velocity values (from $10 \mathrm{~m} / \mathrm{s}$ to more than $60 \mathrm{~m} / \mathrm{s}$ for $\delta=\varphi_{m}=35^{\circ}$ ), a decrease of the flow density (and of the coordination number) and an increase of the flow thickness (from $3 \mathrm{~m}$ to more than $15 \mathrm{~m}$, respectively). Higher friction angles slow down the particles at the interface, generating an increasing velocity gradient associated with a larger variation of velocity vector orientations. Movies of the numerical simulations (not shown here) attest to the rotation of the asymmetrical particles at the vicinity of the interface, which plays a major role in the generation of flow turbulence. The plots of two flow parameters, the coordination number $\zeta$ and the mean particle velocity $V_{m}$, as a function of the friction angle $\delta=\varphi_{m}$ (Figure 7a) show a continual decrease with the friction angle until a stable value $\left(\zeta=0.2 ; V_{m}=43 \mathrm{~m} / \mathrm{s}\right)$ is reached at about $\delta=\varphi_{m}=29^{\circ}$. Beyond this threshold value, the flow regime appears to be little influenced by the friction parameters given the other conditions in the numerical modeling. Considering the deposit characteristics, friction angles have little influence on the position of the center of mass of the deposit, as shown by the slight increase in travel angle values plotted in Figure $7 \mathrm{~b}$. On the contrary, the Fahrböschung $F$ regularly decreases with increasing friction angles, as a result of the spreading of the particles shown by the increase of the standard deviation $\sigma$ from $59 \mathrm{~m}$ to more
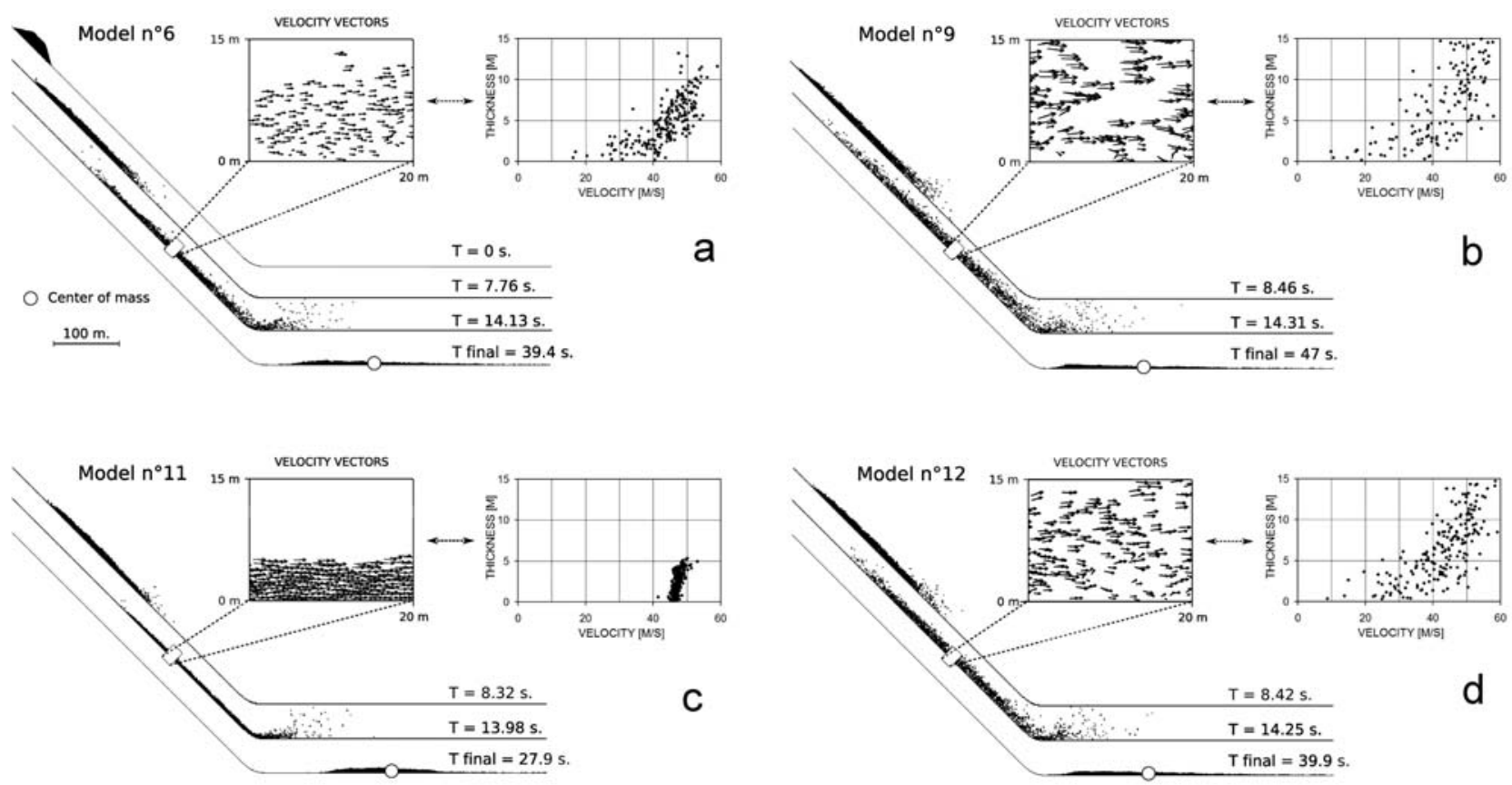

Figure 6. Snapshots of C-type particle flows for four friction parameter sets. Here (a) $\varphi_{m}=\delta=28^{\circ}$, (b) $\varphi_{m}=\delta=35^{\circ}$, (c) $\varphi_{m}=35^{\circ} ; \delta=25^{\circ}$, and (d) $\varphi_{m}=35^{\circ} ; \delta=30^{\circ}$. CRd $=C R s=1$ for all experiments. An enlargement of the particle velocity vectors is shown around $15 \mathrm{~s}$ over a $20 \mathrm{~m}$ wide box located at $1 / 3$ of the fall height as well as the corresponding velocity profile. 

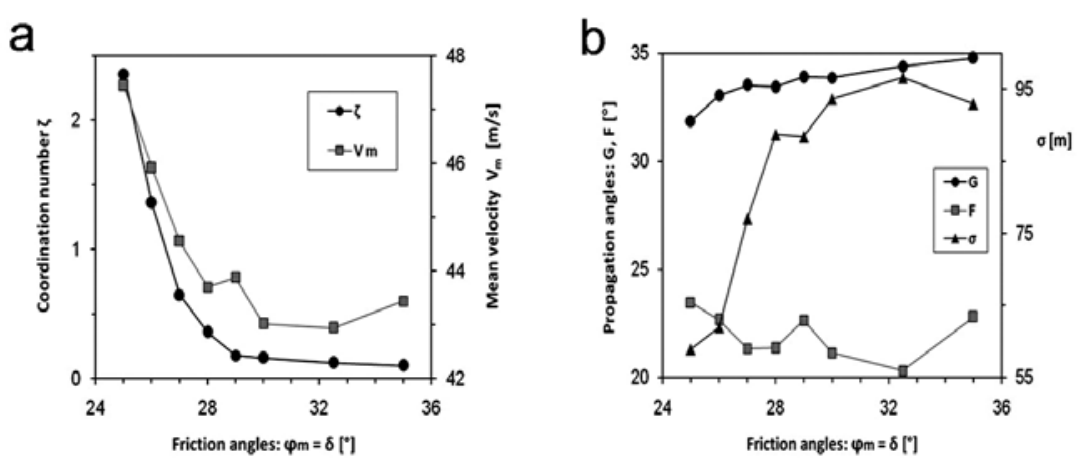

Figure 7. (a) Flow parameters (coordination number $\zeta$ and $V_{m}$ ) as a function of the friction angles $\varphi_{m}=\delta$. (b) Deposit parameters (propagation angles $G, F$, and $\sigma$ ) as a function of friction angles $\varphi_{m}=\delta$.

than $90 \mathrm{~m}$ (Figure $7 \mathrm{~b}$ ) and of the deposit length (Table 2). This friction influence on the spreading is particularly significant below the threshold value of $29^{\circ}$. Evolution of $F$ and $\sigma$ can be explained by the dispersion of the particle velocity values, which increases the distance between proximal and distal particles in the deposit, while the slight increase of the travel angle $G$ results from the decrease of the mean particle velocity $V_{m}$ with the friction angle.

[15] In three additional model runs (10 to 12) friction between particles $\varphi_{m}$ has been set higher than the basal friction $\delta$ (Table 2). Results for models 11 and 12 are shown in Figures $6 \mathrm{c}$ and $6 \mathrm{~d}$, respectively. For models 10 and 11 $\left(\delta=25^{\circ}\right.$ and $\varphi_{m}=30^{\circ}$ and $35^{\circ}$, respectively), numerical results are similar or close to the ones obtained for model $3\left(\delta=\varphi_{m}=25^{\circ}\right.$; compare Figures $4 \mathrm{c}$ and $6 \mathrm{c}$, and flow and deposit parameter values in Table 2) whatever the interparticle friction value. Increasing the basal friction $\delta$ to $30^{\circ}$ for $\varphi_{m}=35^{\circ}$ (model 12 ) leads to particle velocity profiles (Figure 6d) which are intermediate between those of models $6\left(\delta=\varphi_{m}=28^{\circ}\right.$, Figure 6a) and $9\left(\delta=\varphi_{m}=35^{\circ}\right.$, Figure $\left.6 \mathrm{~b}\right)$. Flow and deposit parameters are similar to those obtained for model $8\left(\delta=\varphi_{m}=30^{\circ}\right.$, see Table 2$)$. All these results highlight the prominent role of the basal friction $\delta$ and the limited influence of interparticle friction on the flow regime and on deposit geometry, for the numerical experiments undertaken here.

\subsection{Sensitivity to Rebound Coefficients}

[16] We finally studied the influence of the two rebound coefficients $C R d$ and $C R s$ controlling the energy dissipated during impacts between two particles and between the substratum and a particle, respectively. The snapshots and the velocity fields during the C-type particle flows for three sets of rebound coefficient values are provided in Figure 8. In the first case we only allowed energy dissipation during impacts between particles (model 13; $C R d=0.2 ; C R s=1$ ). Flow and deposit characteristics (Figure $8 \mathrm{a}$ and Table 2) are very similar to those observed for model 3 (Figure 4c, highlighting the limited influence of the rebound coefficient between particles in this case. The granular mass flows uniformly as a dense and thin layer of packed particles, and dissipates little energy through particle shocks. In model 14, energy is dissipated during impacts of particles with the substratum $(C R s=0.2)$ while $C R d$ equals to 1 . The influence of a decrease of $C R s$ on both the flow and the deposit shape is very significant (Figure $8 \mathrm{~b}$ and Table 2). During propa- gation, particles are strongly slowed at the substratum surface, causing particle rotations which disturb the flow and increase its thickness (beyond $15 \mathrm{~m}$ ) and porosity $(\zeta=0.2)$, and generating a strong velocity gradient (from a few $\mathrm{m} / \mathrm{s}$ to $60 \mathrm{~m} / \mathrm{s}$ ) associated with a lower mean velocity $\left(V_{m}=38.8 \mathrm{~m} / \mathrm{s}\right)$. Compared to model $13(C R d=0.2$; $C R s=1$ ), these velocity characteristics result in a decrease of the propagation distance of the center of mass, as shown by the increase of the travel angle $G\left(38^{\circ}\right)$, and a greater dispersion of the particles as attested by the increase of the runout distance, of the deposit length and of the standard deviation values. In model 15 , the two energy dissipation mechanisms during shocks are considered $(C R d=0.2$; $C R s=0.2$ ). Contrary to model 14 , the rebound coefficient between particles $C R d$ here contributes to slowing the particles $\left(V_{m}=33.3 \mathrm{~m} / \mathrm{s}\right)$ and to making the flow denser $(\zeta=0.7$; compare Figures $8 \mathrm{~b}$ and $8 \mathrm{c})$. The effect of $C R d$ is made possible due to the velocity gradient in the flow and the resulting energetic impacts between particles, which do not exist when $C R s=1$ (models 3 and 13). The combined loss of energy (between particles and at the substratum surface) strongly affects the deposit location, length and shape, resulting in a short runout distance $(L=538.5 \mathrm{~m})$, high propagation angles $\left(G=42.6^{\circ} ; F=34.3^{\circ}\right)$ and a compact $\left(L_{f}=185.4 \mathrm{~m} ; \sigma=29.8 \mathrm{~m}\right)$ and thick deposit $\left(T_{f}=17.9 \mathrm{~m}\right)$ spread over the slope break (Figure 8c). Other simulations (not shown) were performed with intermediate values $(C R d=C R s=0.4,0.6$ and 0.8$)$ and lead to the same conclusions.

\subsection{Results}

[17] This 2-D parametric study simulating the release of C-type particles on a steep slope $\left(45^{\circ}\right)$ has identified the prominent role of three parameters on the particle flow and deposit characteristics: the particle shape, the basal friction angle $\delta$ and the rebound coefficient of the substratum CRs. Compared to the unrealistic case of disc-shaped particles (type A), flatter and asymmetrical particles (types B and C) yield denser flows, a lower mobility and produce less spread-out deposits. The introduction of energy dissipation mechanisms at the substrate surface (high basal friction angle and low rebound coefficient) slows down the particles at the bottom of the flow, and increases the velocity gradient and turbulence within the flow. This effect is particularly marked with flat and asymmetrical particles (type $\mathrm{C}$ ). The control of CRs on the runout distance and on the deposit 

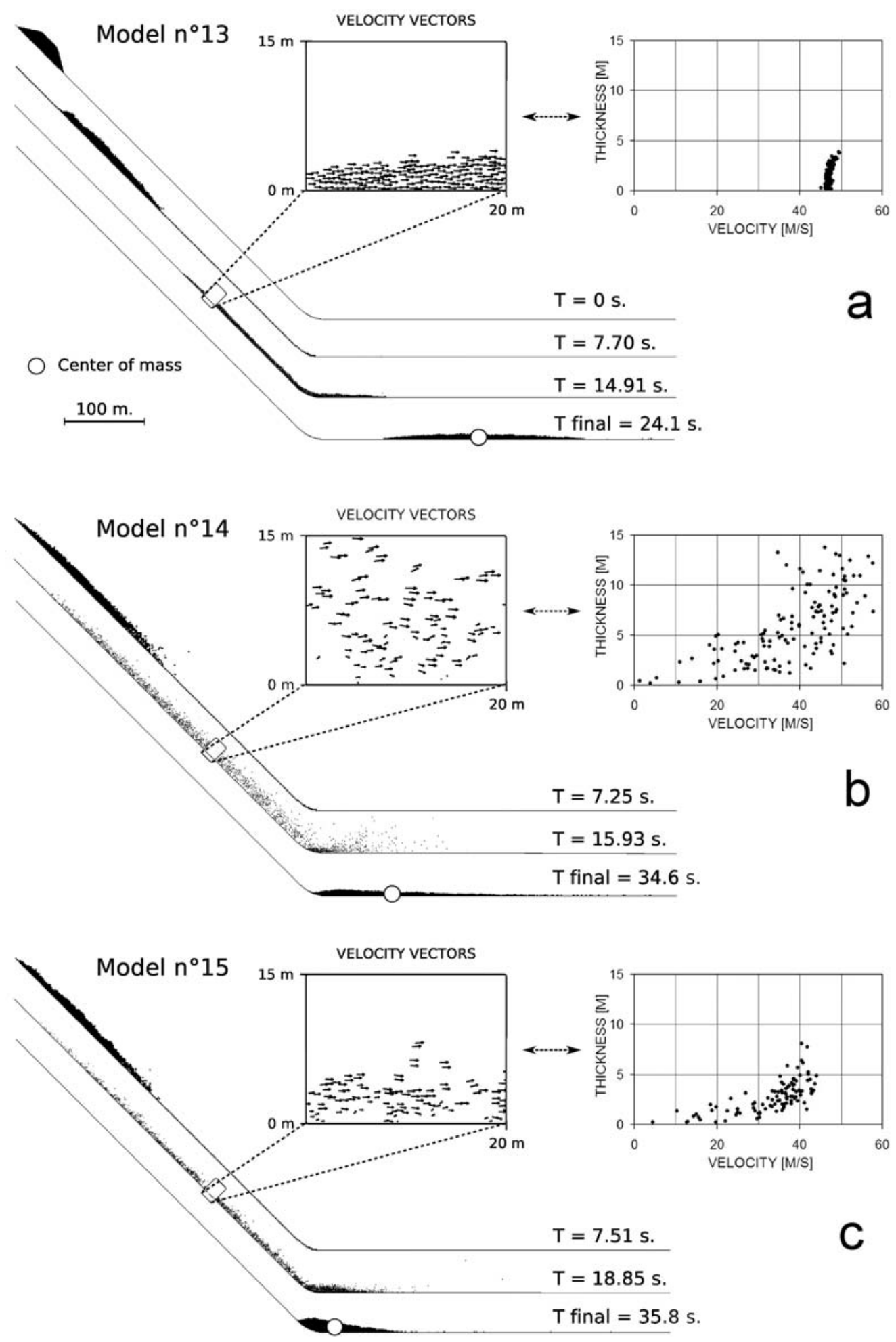

Figure 8. Snapshots of C-type particle flows for three rebound coefficient sets. (a) $C R d=0.2$ and $C R s=1$. (b) $C R d=1$ and $C R s=0.2$. (c) $C R d=C R s=0.2$. Here $\varphi_{m}=25^{\circ}$ and $\delta=25^{\circ}$. An enlargement of the particle velocity vectors is shown around $15 \mathrm{~s}$ over a $20 \mathrm{~m}$ wide box located at $1 / 3$ of the fall height as well as the corresponding velocity profile.

characteristics appears to be stronger than that of the friction angle $\delta$. The rebound coefficient between particles only has an influence on the flow and the deposit characteristics when the velocity gradient within the flow is high enough, allowing significant energy dissipation during impacts. Other numerical simulations performed with B-type particles (not shown) led to the same conclusions on the main parameters controlling the particle avalanche along a steep 
Table 3. Characteristics of the Three Simulated Experiments From Hutter and Koch [1991] and Hutter et al. [1995] ${ }^{\mathrm{a}}$

\begin{tabular}{|c|c|c|c|c|c|c|c|}
\hline Experiment & Material & $\begin{array}{c}\text { Weight } \\
(\mathrm{g})\end{array}$ & $\begin{array}{c}\text { Number of } \\
\text { Particles }\end{array}$ & $\begin{array}{l}\text { Inclination of } \\
\text { Chute (deg) }\end{array}$ & Bed Lining & $\begin{array}{c}\text { Bed Friction } \\
\text { Angle } \delta(\text { deg })\end{array}$ & $\begin{array}{c}\text { Angle of Repose } \\
\varphi(\mathrm{deg}) \\
\end{array}$ \\
\hline 87 & Vestolen & 1500 & $\sim 50,000$ & 50 & Drawing paper & $20-23$ & 29 \\
\hline 97 & Vestolen & 2000 & $\sim 67,000$ & 50 & Sand paper 120 SIA & 28.5 & 33.5 \\
\hline 117 & Glass & 4000 & $\sim 100,000$ & 60 & Drawing paper & 26 & 28 \\
\hline
\end{tabular}

${ }^{\mathrm{a}}$ All bed friction angles are affected by an uncertainty of about $2^{\circ}$.

slope. Having reached an understanding of the effects of the parameters, we have then tried to validate the DEM method against well-controlled laboratory experiments for which input parameters are given.

\section{Validation of DEM With Laboratory Experiments}

\subsection{Experiment Description}

[18] We simulated three laboratory experiments carried out by Savage and Hutter [1991] and Hutter et al. [1995] on the motion of several cohesionless granular materials. The channelized experiments were performed with a $10 \mathrm{~cm}$ wide chute consisting of three portions: a straight plane with an inclination $\alpha$ from $50^{\circ}$ to $60^{\circ}$, a curved part and a horizontal plane. The sidewalls consisted of smooth material in order to keep the flow as two dimensional as possible. The granular mass $M$ was placed at the top of the chute and was released by opening a shutter. The moving granular mass was photographed seven times per second. These experiments were chosen for DEM validation because of the considerable effort dedicated to the measurement of the rheological parameters of the lining and of the particles, which will be used as input parameters in the modeling. As the granular flow is channelized, 2-D DEM can be applied for modeling the flow, neglecting the effect of the sidewalls. The three physical experiments chosen (labeled 87, 97, and 117 , as in the original papers) used two materials, nearly spherical glass beads and lens-like-shaped plastic particles (called vestolen), with different volumes and bed linings (drawing paper and sandpaper). Table 3 shows all the experimental setup characteristics given by Hutter et al. [1995]. Savage and Hutter [1991] and Hutter and Koch [1991] made several attempts to measure the bed friction and internal friction angles, using different techniques. Bed friction angles were determined on portions of drawing paper and sandpaper after the tests had been completed and it is likely that the successive experiments gradually wore down the lining. Hence, the given values of bed friction angle are probably lower than those existing during the experiments [Savage and Hutter, 1991]. Moreover, an uncertainty of about $2^{\circ}$ was found in the mean bed friction angle values [Hutter et al., 1995]. The internal friction angle $\varphi_{m}$ was correlated by the same authors to the angle of repose $\varphi$ of a wedge-type pile made of the granular material deposited on a horizontal plane covered with drawing paper or sand paper. The angles of repose were accurate to at most $\pm(2-4){ }^{\circ}$ owing to the effect of scoring and measurement inaccuracy [Hutter et al., 1995]. Fortunately, previous results [Hutter and Koch, 1991; Savage and Hutter, 1991; Hutter et al., 1995] and our modeling tests have shown that the mass propagation is not very sensitive to the internal friction angle variations. The properties of the two materials (vestolen particles and glass beads), as well as the measured restitution coefficients between the particles and the lining, are given in Table 4.

\subsection{Numerical Setup}

[19] We simulated the three experiments using 1839 to 4042 particles, with a circular shape (glass beads) or with a 2-D clump shape and an aspect ratio $d / R=1.2$ (vestolen particles). Considering the channel width $(10 \mathrm{~cm})$ and the nominal diameters for the vestolen $(4 \mathrm{~mm})$ and glass beads $(3 \mathrm{~mm})$, the number of 2-D particles approximately coincides with those of the 3-D physical experiment particles existing along a section through the middle of the channel $(50,000$ divided by 25 for experiment 87 and 100,000 divided by 33 for experiment 117). The aspect ratio of 1.2 was chosen to fit with the lens shape of the vestolen particles. For the contact between particles and the lining, we directly took the mean restitution coefficient values determined by Hutter and Koch [1991] and given in Table 4. Even if these were obtained from rebound measurements on 3-D particles, they were used directly in 2-D numerical modeling, as their values only depend on approaching and rebound velocities. Two-dimensional porosity values were taken in the same range as those given in Table 4. Tests have however shown that the influence of initial porosity on the granular flow is not significant. For experiments 97 and 117, bed friction angle values were directly extracted from Table 3 . For experiment 87 , the bed friction angle uncertainty is higher $\left(20-23^{\circ} \pm 2^{\circ}\right)$ and we took the value $\delta=19^{\circ}$ which gave the best fit in the possible range, and in agreement with additional values $\left(20^{\circ} \pm 1.5^{\circ}\right)$ measured for unworn drawing paper by Hutter et al. [1995].

Table 4. Material Properties From Savage and Hutter [1991], Hutter and Koch [1991], and Hutter et al. [1995]

\begin{tabular}{|c|c|c|c|c|c|c|}
\hline Material & Shape & Size & $\begin{array}{l}\text { Particle } \\
\text { Density }\end{array}$ & $\begin{array}{c}\text { Bulk } \\
\text { Density }\end{array}$ & $\begin{array}{c}\text { Porosity } \\
(\%)\end{array}$ & Restitution Coefficient $R e$ \\
\hline Vestolen & Lens-type & $\begin{array}{c}\text { Diameter } 4 \mathrm{~mm} \text {; } \\
\text { Height } 2.5 \mathrm{~mm}\end{array}$ & $950 \mathrm{~kg} / \mathrm{m}^{3}$ & $540 \mathrm{~kg} / \mathrm{m}^{3}$ & 42 & $\begin{array}{l}\text { Drawing paper, } 0.61 \pm 0.04 \\
\quad \text { Sand paper, } 0.54 \pm 0.06\end{array}$ \\
\hline Glass & Spherical beads & $3 \mathrm{~mm}$ diameter & $2860 \mathrm{~kg} / \mathrm{m}^{3}$ & $1730 \mathrm{~kg} / \mathrm{m}^{3}$ & 35 & $\begin{array}{l}\text { Drawing paper, } 0.48 \pm 0.03 ; \\
\quad \text { Sand paper, } 0.67 \pm 0.05\end{array}$ \\
\hline
\end{tabular}

${ }^{a}$ Restitution coefficients were obtained using $R e=\sqrt{ }\left(h_{1} / h_{0}\right)$ where $h_{0}$ and $h_{1}$ are the heights of fall and bounce, respectively. 
Table 5. Bed and Microscopic Friction Values Taken for Numerical Modeling

\begin{tabular}{ccccc}
\hline & & $\begin{array}{c}\text { Number and } \\
\text { Type of } \\
\text { Particles }\end{array}$ & $\begin{array}{c}\text { Med Friction } \\
\text { Angle } \delta(\mathrm{deg})\end{array}$ & $\begin{array}{c}\text { Microscopic } \\
\text { Friction Angle } \\
\varphi_{m}(\mathrm{deg})\end{array}$ \\
\hline 87 & Vestolen & $\begin{array}{c}1839 ; \text { Clumps } \\
\text { with } d / R=1.2\end{array}$ & 19 & 28.5 \\
97 & Vestolen & $\begin{array}{c}2740 ; \text { Clumps } \\
\text { with } d / R=1.2\end{array}$ & 28.5 & 28.5 \\
117 & Glass & 4042; Circular discs & 26 & 26 \\
\hline
\end{tabular}

The microscopic friction angle $\varphi_{m}$ was set indirectly. $\mathrm{Nu}-$ merical simulations were performed to reproduce the angle of repose of a pile of the granular material sited on a horizontal plane covered with fixed particles (bed friction angle equivalent to the macroscopic internal friction angle). This layout was chosen in order to obtain a value of $\varphi_{m}$ independent of the lining and characterizing the material. We found $\varphi_{m}=28.5^{\circ}$ and $26^{\circ}$ for the vestolen particles and the glass beads, to obtain angles of repose of $33.5^{\circ}$ and $28^{\circ}$, respectively. The main parameters considered in the numerical modeling are summarized in Table 5.

[20] In the numerical modeling, the initial profile shape of the granular material was triangular (Figure 9, $T_{0}=0 \mathrm{~s}$ ) in order to control the particle disposal set up easily and to reach the correct bulk density and volume values. As shown by Savage and Hutter [1991], the avalanche development is not too sensitive to the initial profile shape.

\subsection{Numerical Results and Comparison}

[21] In experiment $87,1.5 \mathrm{~kg}$ of vestolen particles was released from rest down an incline $\left(50^{\circ}\right)$ covered with drawing paper. Snapshots of the experiment showed that the propagation lasted $1.44 \mathrm{~s}$ before the mass came to rest (Figure 9). This experiment was simulated numerically using 1839 clumps with $d / R=1.2$. Figure 9 compares the experimental and modeled snapshots at 11 propagation times. Although initial profile shapes are slightly different, the mass propagates down the slope with time in the same way, reaching the horizontal plane after about $0.6 \mathrm{~s}$. At rest,

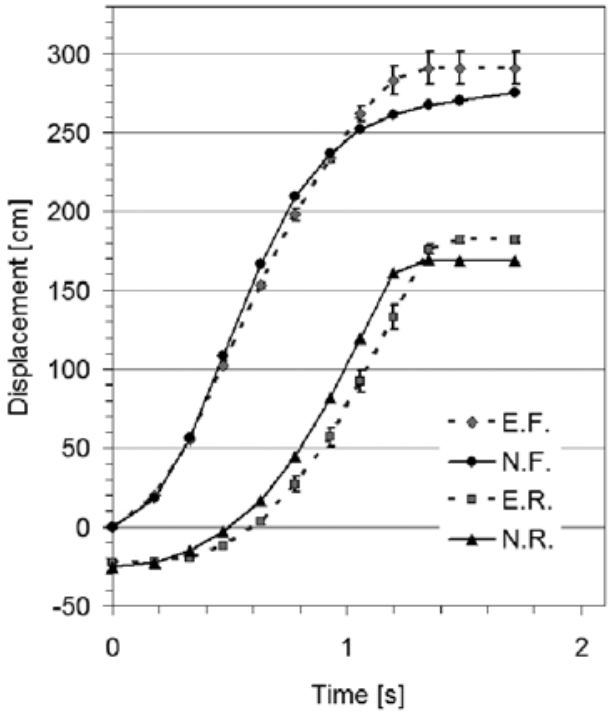

Figure 10. Experimental measurements and computed predictions of leading and trailing edges of experiment 87 . E.F., experimental front; N.F., numerical front; E.R., experimental rear; N.R., numerical rear.

the modeled and observed deposits exhibit the same length and asymmetric shape with a higher rear slope. Comparison of leading and trailing edge positions (Figure 10) shows that the simulated and experimental front ends travel similarly during the first two thirds of the experiment. However, the experimental front goes further but decelerates quicker than the simulated one. On the contrary, the simulated rear end propagates slightly quicker than the experimental one before abruptly decelerating and reaching a final nearer position. It must be noticed that the biggest discrepancies are observed for the front end at the end of the experiment when experimental error bars are higher. Considering all uncertainties on both data and input parameters, the agreement between experimental results and numerical
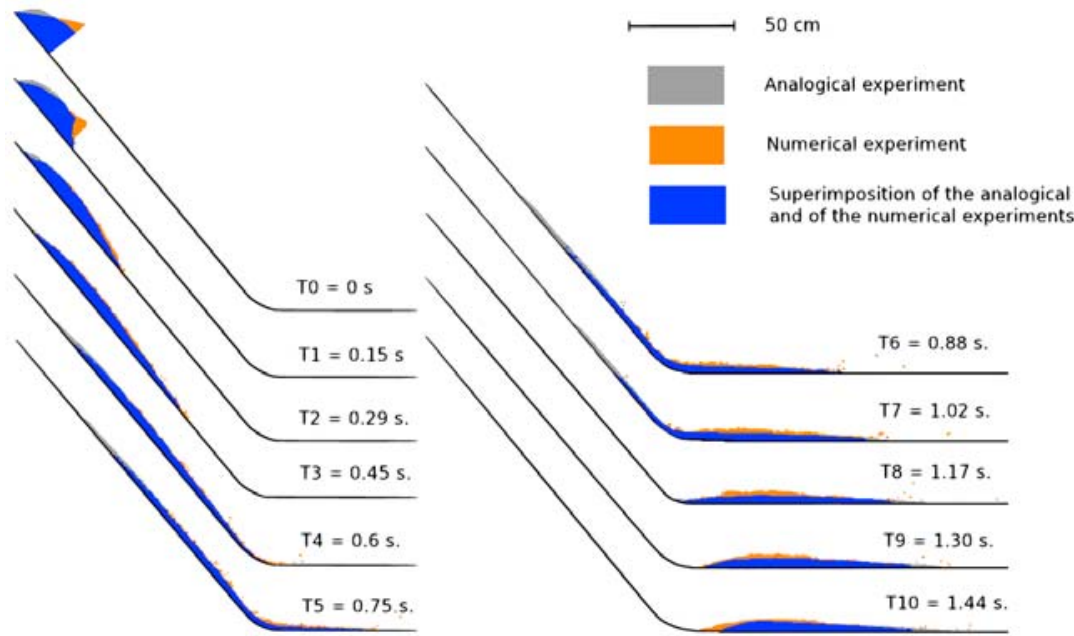

Figure 9. Comparison between snapshots of experiment 87 (gray) [Savage and Hutter, 1991] and of DEM simulations (orange) at 11 travel times. Common parts are in blue. 


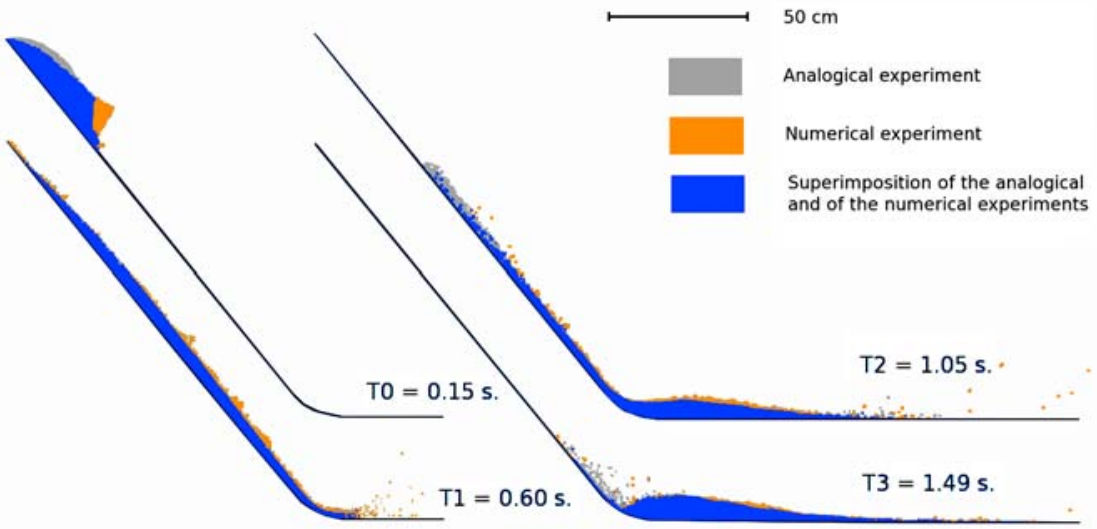

Figure 11. Comparison between snapshots of experiment 97 (gray) [Hutter et al., 1995] and of DEM simulations (orange) at four travel times. Common parts are in blue.

simulations is very good. Air resistance could have affected these lightweight particles but a simple calculus shows that the air resistance force acting on the flow front is less than $0.1 \%$ of the gravity driven force. This negligible effect of the air resistance is corroborated by the work of Lube et al. [2004], who experimentally explored the effect of grain density on granular slumping.

[22] In the second experiment (97), a $2 \mathrm{~kg}$ mass of about 67,000 vestolen particles moved down a chute with an inclination angle of $50^{\circ}$ over a surface coated with sand paper. The 2-D simulation was made with 2740 clumped particles with an aspect ratio $d / R=1.2$. Figure 11 compares the experimental and simulated snapshots at 4 different times. Comparing with experiment 87 , the runout of the mass and the deposit length are shorter, and the deposit shape is strongly asymmetrical, owing to the higher bed friction angle $\left(28.5^{\circ}\right.$ instead of $\left.19^{\circ}\right)$. All these features in the simulation results are remarkably consistent with the experimental ones. A striking feature appearing on both sets of snapshots and mentioned by Hutter et al. [1995] is the substantial ejection of particles affecting the immediate front and a considerable part of the tail, resulting from the higher basal friction. The only discrepancy is the slight delay observed between the experimental and simulated rear ends at the end of the experiment, owing to this high particle agitation.

[23] In experiment 117 , a mass of $4 \mathrm{~kg}$ of glass beads (about 100,000 round particles) was released down an incline of $60^{\circ}$ covered with drawing paper. Experimental snapshots are given in Figure 12. As expected, the run out distance and the spreading are much larger than in the two previous experiments, owing to the particle shape and the relatively low bed friction angle. Also, the obtained deposit shape is more symmetrical. In this case, the initial experimental initial profile of the granular material has a triangular shape and is perfectly matched by the numerical one (Figure 12, $T_{0}$ ). From the comparison of the two sets of snapshots it appears that the mass propagation with time, along with the final position and shape of the deposit, is very well simulated by the DEM method. A minor discrepancy is

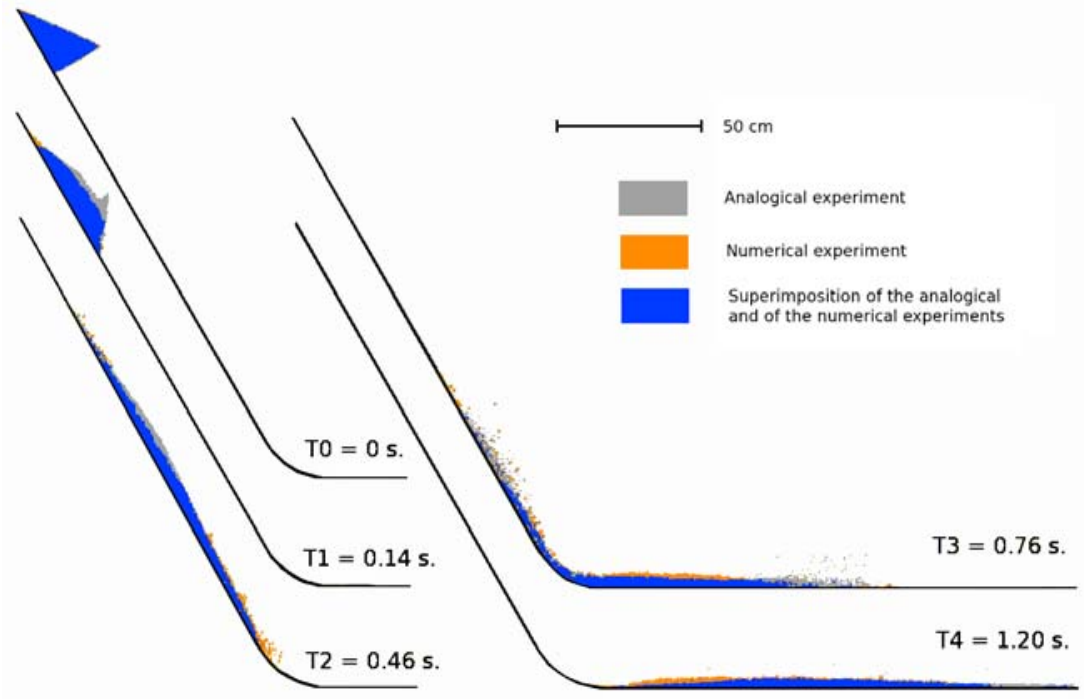

Figure 12. Comparison between snapshots of experiment 117 (gray) [Hutter et al., 1995] and of DEM simulations (orange) at five travel times. Common parts are in blue. 
visible at $T_{1}=0.14 \mathrm{~s}$, when the mass propagation in the physical experiment is disturbed by the rotating gate which is not fully open. This temporary disturbance has however little influence on the avalanche, in agreement with the conclusions drawn by Savage and Hutter [1991].

\section{Conclusions}

[24] We applied the discrete element method to simulate avalanches of monodisperse granular material. The use of spherical (circular in 2-D) particles enhances particle rolling and yields excess runout values. Instead of introducing a force damping which artificially slows down the particle velocities, we studied the mechanisms dissipating energy through collisions between particles, and between particles and the substratum. Considering the particle and basal surface properties (particle shape, friction and rebound coefficients), we first performed a parametric analysis on a simple 2-D model. Numerical results pointed out the prominent effect of the particle shape and the friction and rebound coefficient of the basal surface on the flow dynamics and on the deposit geometry. The rebound coefficient between particles could play a role when the flow is turbulent with a large velocity gradient, while the influence of interparticle friction is minor. In a second step, we simulated three previous channelized laboratory experiments using different material types, bed linings and geometries. Introducing the layout and the mechanical characteristics provided by the authors, we obtained a remarkable agreement between the observed and simulated deposit shapes for the three experiments. Also, the computed mass propagation at different times is very consistent with the experimental snapshots. These results show that the DEM technique is capable of handling the physical processes during channelized laboratory experiments of unigranular mass avalanches, when the relevant input parameters are known. This contribution highlights the valuable use of the DEM technique for understanding the mobility of granular material avalanches. Application to real cases requires however evaluation of input parameters (friction angles and coefficients of restitution), which is a delicate task. A way to calibrate these parameters is to perform back analysis of well documented events, as it was done by Pirulli and Mangeney [2008] for the rock avalanches of Frank and Val Pola, and by Sosio et al. [2008] for the Thurwieser rock avalanche, using a continuum mechanics approach. For determining the restitution coefficient $R_{e}$, an alternative way would be to install fast camera images in rockfall prone areas to measure the block velocities before and after the impacts. For real case applications, poly disperse materials should also be introduced in DEM simulations. So far, the maximum diameter ratio $\mathrm{d} 1 / \mathrm{d} 2$ considered in DEM for bidisperse material is between five [Cleary and Campbell, 1993] and eight [Linares-Guerrero et al., 2007; Rognon et al., 2007]. These values are 4 orders of magnitude lower than those encountered for real rock avalanche deposits, like the Val Pola one in which the particle size ranges from fine sand to boulder [Crosta et al., 2007]. Handling particles with such a wide size range could be possible in the future by coupling DEM and SPH (Smoothed Particle Hydrodynamics), with DEM representing the coarse particles and SPH modeling the fine material as a non-Newtonian fluid [Cleary and Prakash, 2004].

\section{Notation}

$C R$ coefficient of rebound, based on the height of bounce $\left(C R=h_{1} / h_{0}\right)$, dimensionless.

$C R d$ coefficient of rebound between two particles, dimensionless.

CRs coefficient of rebound between the substratum and a particle, dimensionless.

$d$ distance between the centers of two discs of one particle, $m$.

$F$ Fahrböschung, ${ }^{\circ}$.

$F_{k}$ component $k$ of the whole contact forces acting on a particle, $\mathrm{N}$.

$F_{n}$ normal contact force between two particles N.

$F_{S}$ tangential contact force between two particles, N.

$G$ travel angle of the granular assembly, 。

$G_{f}$ final position of the center of mass of the granular assembly, $\mathrm{m}$.

$G_{i}$ initial position of the center of mass of the granular assembly, $\mathrm{m}$.

$H$ fall height of the granular assembly, $\mathrm{m}$.

$h_{0}$ height of fall of one particle, $\mathrm{m}$.

$h_{1}$ height of bounce of one particle, $\mathrm{m}$.

$K_{n}$ normal stiffness of the contact between two particles, $\mathrm{N} / \mathrm{m}$.

$k_{n i} \quad$ normal stiffness for particle $i, \mathrm{~N} / \mathrm{m}$.

$k_{n s}$ normal stiffness for the substratum, $\mathrm{N} / \mathrm{m}$.

$K_{s}$ shear stiffness of contact between two particles, $\mathrm{N} / \mathrm{m}$.

$k_{s i}$ shear stiffness for particle $i, \mathrm{~N} / \mathrm{m}$.

$k_{s s} \quad$ shear stiffness for the substratum, N/m.

$L$ runout horizontal distance of the granular assembly, m.

$L_{f}$ final basal length of the granular assembly, $\mathrm{m}$.

$L_{i} \quad$ initial basal length of the granular assembly, $\mathrm{m}$.

$M$ mass of the granular assembly, $\mathrm{kg}$.

$m$ mass of one particle, $\mathrm{kg}$.

$N_{c}$ number of particles of the granular assembly, dimensionless.

$N_{d}$ number of particles used for the definition of the flowing parameters, dimensionless.

$R c$ curvature radius of the circular section at the base of the inclined plane, $\mathrm{m}$.

$R e$ restitution coefficient based on the velocities $(\mathrm{Re}=$ $\mathrm{V}_{\mathrm{f}}\left(\mathrm{V}_{\mathrm{i}}\right)$.

$R_{i} \quad$ radius of disc $\mathrm{i}$ of one particle, $\mathrm{m}$.

$R_{s}$ shear strength limit of contact, $\mathrm{N}$.

$R_{t}$ tensile strength limit of contact, N.

$S_{f}$ shape factor of one particle, dimensionless.

$T$ travel time of the granular assembly, $\mathrm{m}$.

$T_{f}$ final thickness of the granular assembly, $\mathrm{m}$.

$T_{i}$ initial thickness of the granular assembly, $\mathrm{m}$.

$t_{s}$ time at which the flowing parameters have been determined, s.

$U_{n}$ normal overlap between two particles, $\mathrm{m}$.

$U_{t}$ tangential relative displacement between two particles, $\mathrm{m}$.

$V_{f}$ normal particle velocities after rebound, $\mathrm{m} / \mathrm{s}$.

$V_{i}$ normal particle velocities before rebound, $\mathrm{m} / \mathrm{s}$. 
$V_{k}$ component $k$ of the velocity of one particle, $\mathrm{m} / \mathrm{s}$.

$V_{m}$ mean velocity of the particles, $\mathrm{m} / \mathrm{s}$.

$X_{\text {front }}$ front position of the deposit, $\mathrm{m}$.

$X_{\text {rear }}$ rear position of the deposit, $\mathrm{m}$.

$\alpha$ slope angle of the inclined plane, ${ }^{\circ}$.

$\beta$ basal angle of the initial trapezoidal box, ${ }^{\circ}$.

$\delta$ microscopic friction angle of the substratum, ${ }^{\circ}$.

$\zeta$ coordination number, dimensionless.

$\varphi$ angle of repose of a wedge-type pile made of granular material, ${ }^{\circ}$.

$\varphi_{m}$ microscopic friction angle of contact, ${ }^{\circ}$.

$\varphi_{m i} \quad$ microscopic friction angle of particle $i,{ }^{\circ}$.

$\gamma_{k}$ component $k$ of acceleration of one particle, $\mathrm{m} / \mathrm{s}^{2}$.

$\sigma$ standard deviation of the particle distribution around the center of mass, $\mathrm{m}$.

$\chi$ force damping coefficient, dimensionless.

[25] Acknowledgments. This study was performed with a grant of the French Italian University. We thank the three anonymous reviewers and the Associate Editor for their valuable comments and fruitful suggestions.

\section{References}

Allen, M. P., and D. J. Tildesley (1987), Computer Simulation of Liquids, 408 pp., Oxford Sci., New York.

Calvetti, F., G. B. Crosta, and M. Tatarella (2000), Numerical simulation of dry granular flows: From the reproduction of small-scale experiments to the prediction of rock avalanches, Riv. Ital. Geotecnica, 34, 21-38.

Campbell, C. S., P. W. Cleary, and M. Hopkins (1995), Large-scale landslide simulations: Global deformation, velocities and basal friction, J. Geophys. Res., 100, 8267-8283, doi:10.1029/94JB00937.

Chareyre, B., and P. Villard (2005), Dynamic spar elements and discrete element methods in two dimensions for the modeling of soil-inclusion problems, J. Eng. Mech., 131, 689-698, doi:10.1061/(ASCE)07339399(2005)131:7(689).

Cleary, P. W., and C. S. Campbell (1993), Self-lubrication for long-runout landslides: Examination by computer simulation, J. Geophys. Res., 98 , 21,911-21,924.

Cleary, P. W., and M. Prakash (2004), Discrete-element modelling and smoothed particle hydrodynamics: Potential in the environmental sciences, Philos. Trans. R. Soc. A, 362, 2003-2030.

Corominas, J. (1996), The angle of reach as a mobility index for small and large landslides, Can. Geotech. J., 33, 260-271, doi:10.1139/t96-005.

Crosta, G. B., F. Calvetti, S. Imposimato, D. G. Roddeman, P. Frattini, and F. Agliardi (2001), Granular flows and numerical modelling of landslides, Rep. EVG1-CT-1999-00007, 70 pp., Univ. Milano Bicocca, Milan, Italy.

Crosta, G. B., S. Imposimato, and D. G. Roddeman (2003), Numerical modelling of large landslides stability and runout, Nat. Hazards Earth Syst. Sci., 3, 523-538.

Crosta, G. B., P. Frattini, and N. Fusi (2007), Fragmentation in the Val Pola rock avalanche, Italian Alps, J. Geophys. Res., 112, F01006, doi:10.1029/ 2005JF000455.

Cundall, P. A. (1971), A computer model for simulating progressive large scale movements in blocky rock systems, in Rock Fracture: Proceedings of the Symposium of the International Society of Rock Mechanics 4-6th October, pp. 132-150, École natl. supér. de géol. Appl. et de prospect. min., Nancy, France.

Cundall, P. A. (1987), Distinct element models of rock and soil structure, Analytical and Computational Methods in Engineering Rock Mechanics, edited by E. T. Brown, pp. 129-163, Allen and Unwin, London.

Cundall, P. A., and O. D. L. Strack (1979), Discrete numerical model for granular assemblies, Geotechnique, 29, 47-65.

Davies, T. R., and M. J. McSaveney (1999), Runout of dry granular avalanches, Can. Geotech. J., 36, 313-320, doi:10.1139/cgj-36-2-313.

Davies, T. R., and M. J. McSaveney (2002), Dynamic simulation of the motion of fragmenting rock avalanches, Can. Geotech. J., 39, 789-798, doi:10.1139/t02-035.

Davies, T. R., M. J. McSaveney, and K. A. Hodgson (1999), A fragmentation-spreading model for long-runout rock avalanches, Can. Geotech. J., 36, 1096-1110, doi:10.1139/cgj-36-6-1096.

Deluzarche, R., B. Cambou, and J. J. Fry (2003), Modeling of rockfill behaviour with crushable particles, in First International PFC Symposium, edited by H. Konietzky, pp. 125-131, AA Balkema, Gelsenkirchen, Germany.
Denlinger, R. P., and R. M. Iverson (2001), Flow of variably fluidized granular masses across three-dimensional terrain: 2. Numerical predictions and experimental tests, J. Geophys. Res., 106, 553-566, doi:10.1029/2000JB900330.

Denlinger, R. P., and R. M. Iverson (2004), Granular avalanches across irregular three-dimensional terrain: 1 . Theory and computation, J. Geophys. Res., 109, F01014, doi:10.1029/2003JF000085.

Erismann, T. H., and G. Abele (2001), Dynamics of Rockslides and Rockfalls, 316 pp., Springer, Berlin.

Evans, S. G., and O. Hungr (1993), The assessment of rockfall hazard at the base of talus slopes, Can. Geotech. J., 30, 620-636, doi:10.1139/t93-054.

Friedmann, S. J., N. Taberlet, and W. Losert (2006), Rock-avalanche dynamics: Insights from granular physics experiments, Int. J. Earth Sci., 95, 911-919, doi:10.1007/s00531-006-0067-9.

Goujon, C., N. Thomas, and B. Dalloz-Dubrujeaud (2003), Monodisperse dry granular flows on inclined planes: Role of roughness, Eur. Phys. J. E, 11, 147-157, doi:10.1140/epje/i2003-10012-0.

Goujon, C., B. Dalloz-Dubrujeaud, and N. Thomas (2007), Bidisperse granular avalanches on inclined planes: A rich variety of behaviors, Eur. Phys. J. E, 23, 199-215, doi:10.1140/epje/i2006-10175-0.

Heim, A. (1932), Bergsturz und Menschenleben, 218 pp., Fretz und Wasmuth, Zürich

Hsu, K. J. (1975), Catastrophic debris streams (sturzstroms) generated by rockfalls, Geol. Soc. Am. Bull., 86, 129-140, doi:10.1130/00167606(1975)86<129:CDSSGB $>2.0$. CO;2.

Hungr, O. (1995), A model for the runout analysis of rapid flow slides, debris flows, and avalanches, Can. Geotech. J., 32, 610-623, doi:10.1139/t95-063.

Hungr, O., and S. G. Evans (2004), Entrainment of debris in rock avalanches: An analysis of a long runout mechanism, Geol. Soc. Am. Bull., 116, 1240-1252, doi:10.1130/B25362.1.

Hungr, O., and N. R. Morgenstern (1984), Experiments on the flow behavior of granular materials at high-velocity in an open channel, Geotechnique, 34, 405-413.

Hutter, K., and T. Koch (1991), Motion of a granular avalanche in an exponentially curved chute: Experiments and theoretical predictions, Philos. Trans. R. Soc. London, Ser. A, 334, 93-138.

Hutter, K., T. Koch, C. Pluss, and S. B. Savage (1995), The dynamics of avalanches of granular materials from initiation to runout: 2. Experiments, Acta Mech., 109, 127-165, doi:10.1007/BF01176820.

Itasca Consulting Group (1996), Particle flow code in two dimensions, Rep. PFC2D, Minneapolis, Minn.

Iverson, R. M., M. Logan, and R. P. Denlinger (2004), Granular avalanches across irregular three-dimensional terrain: 2. Experimental tests, J. Geophys. Res., 109, F01015, doi:10.1029/2003JF000084.

Jean, M. (1999), The non-smooth contact dynamics method, Comput. Methods Appl. Mech. Eng., 177, 235-257, doi:10.1016/S00457825(98)00383-1.

Lajeunesse, E., J. B. Monnier, and G. M. Homsy (2005), Granular slumping on a horizontal surface, Phys. Fluids, 17, 103302, doi:10.1063/1.2087687.

Legros, F. (2002), The mobility of long-runout landslides, Eng. Geol., 63, 301-331, doi:10.1016/S0013-7952(01)00090-4.

Linares-Guerrero, E., C. Goujon, and R. Zenit (2007), Increased mobility of bidisperse granular avalanches, J. Fluid Mech., 593, 475-504, doi:10.1017/S0022112007008932.

Lube, G., H. E. Huppert, R. S. J. Sparks, and M. A. Hallworth (2004), Axisymmetric collapses of granular columns, J. Fluid Mech., 508, 175-199, doi:10.1017/S0022112004009036.

Mangeney-Castelnau, A., J. P. Vilotte, M. O. Bristeau, B. Perthame, F. Bouchut, C. Simeoni, and S. Yerneni (2003), Numerical modeling of avalanches based on Saint Venant equations using a kinetic scheme, J. Geophys. Res., 108(B11), 2527, doi:10.1029/2002JB002024.

Manzella, I., and V. Labiouse (2008), Qualitative analysis of rock avalanches propagation by means of physical modelling of non-constrained gravel flows, Rock Mech. Rock Eng., 41, 133-151, doi:10.1007/s00603007-0134-y.

McDougall, S., and O. Hungr (2004), A model for the analysis of rapid landslide motion across three-dimensional terrain, Can. Geotech. J., 41, 1084-1097, doi:10.1139/t04-052.

McDougall, S., and O. Hungr (2005), Dynamic modelling of entrainment in rapid landslides, Can. Geotech. J., 42, 1437-1448, doi:10.1139/t05-064.

Moreau, J. J. (1988), Unilateral contact and dry friction in finite freedom dynamics, Nonsmooth Mech. Appl., 302, 1-82.

Moreau, J. J. (1993), New computation methods in granular dynamics, Powders Grains, 93, 227-232.

Morgan, J. K., and P. J. McGovern (2003), Discrete element simulations of volcanic spreading: Implications for the structure of Olympus Mons, Lunar Planet. Sci., XXXIV, Abstract 2088.

Morgan, J. K., and P. J. McGovern (2005), Discrete element simulations of gravitational volcanic deformation: 1 . Deformation structures and geometries, J. Geophys. Res., 110, B05402, doi:10.1029/2004JB003252. 
Oger, L., S. B. Savage, D. Corriveau, and M. Sayed (1998), Yield and deformation of an assembly of disks subjected to a deviatoric stress loading, Mech. Mater., 27, 189-210, doi:10.1016/S0167-6636(97)00066-5.

Pfeiffer, T., and T. Bowen (1989), Computer simulation of rockfalls, Bull. Assoc. Eng. Geol., 26, 135-146.

Pirulli, M., and A. Mangeney (2008), Results of back-analysis of the propagation of rock avalanches as a function of the assumed rheology, Rock Mech. Rock Eng., 41, 59-84, doi:10.1007/s00603-007-0143-x.

Pirulli, M., M. O. Bristea, A. Mangeney, and C. Scavia (2007), The effect of the Earth pressure coefficients on the runout of granular material, Environ. Modell. Software, 22, 1437-1454, doi:10.1016/ j.envsoft.2006.06.006

Pouliquen, O., and Y. Forterre (2002), Friction law for dense granular flows: Application to the motion of a mass down a rough inclined plane, J. Fluid Mech., 453, 133-151, doi:10.1017/S0022112001006796.

Radjai, F., D. E. Wolf, M. Jean, and J. J. Moreau (1998), Bimodal character of stress transmission in granular packings, Phys. Rev. Lett., 80, 61-64, doi:10.1103/PhysRevLett.80.61.

Richards, K., M. Bithell, M. Dove, and R. Hodge (2004), Discrete-element modelling: Methods and applications in the environmental sciences, Philos. Trans. R. Soc. London, Ser A, 362, 1797-1816.

Rognon, P. G., J. N. Roux, M. Naaim, and F. Chevoir (2007), Dense flows of bidisperse assemblies of disks down an inclined plane, Phys. Fluids, 19, 058101, doi:10.1063/1.2722242.

Salot, C, P. Gotteland, and P. Villard (2009), Influence of relative density on granular materials behavior: DEM simulations of triaxial tests, Granul. Matter, 11, 221-236, doi:10.1007/s10035-009-0138-2.

Savage, S. B., and K. Hutter (1989), The motion of a finite mass of granular material down a rough incline, J. Fluid Mech., 199, 177-215, doi:10.1017/S0022112089000340.

Savage, S. B., and K. Hutter (1991), The dynamics of avalanches of granular materials from initiation to runout: 1. Analysis, Acta Mech., 86, 201-223, doi:10.1007/BF01175958.
Schäfer, J., S. Dippel, and D. E. Wolf (1996), Force schemes in simulations of granular materials, J. Phys. I, 6, 5-20, doi:10.1051/jp1:1996129.

Sosio, R., G. B. Crosta, and O. Hungr (2008), Complete dynamic modeling calibration for the Thurwieser rock avalanche (Italian central Alps), Eng. Geol., 100, 11-26, doi:10.1016/j.enggeo.2008.02.012.

Staron, L. (2008), Mobility of long-runout rock flows: A discrete numerical investigation, Geophys. J. Int., 172, 455-463, doi:10.1111/j.1365246X.2007.03631.X.

Staron, L., and E. J. Hinch (2007), The spreading of a granular mass: Role of grain properties and initial conditions, Granul. Matter, 9, 205-217, doi: $10.1007 / \mathrm{s} 10035-006-0033-\mathrm{z}$

Valentino, R., G. Barla, and L. Montrasio (2008), Experimental analysis and micromechanical modelling of dry granular flow and impacts in laboratory flume tests, Rock Mech. Rock Eng., 41, 153-177, doi:10.1007/s00603-006-0126-3.

Voellmy, A. (1955), Uber die Zerstorungskraft von Lawinen, Schweiz. Bauztg., 73, 212-285.

Walton, O. R., and R. L. Braun (1986), Viscosity, granular temperature, and stress calculations for shearing assemblies of inelastic, frictional disks, J. Rheol. N. Y., 30, 949-980, doi:10.1122/1.549893.

J. Banton and D. Jongmans, Laboratoire de Géophysique Interne et Tectonophysique, Observatoire des Sciences de l'Univers, Université Joseph Fourier, CNRS, BP 53, F-38041 Grenoble CEDEX 9, France.

C. Scavia, Department of Structural and Geotechnical Engineering, Politecnico di Torino, Corso Duca degli Abruzzi, 24, I-10129 Torino, Italy.

P. Villard, Laboratoire 3S-R, Université Joseph Fourier, G-INP, CNRS, BP 53, F-38041 Grenoble CEDEX 9, France. 